\title{
Visible-Light-Promoted, Catalyst-Free Gomberg-Bachmann Reaction: Synthesis of Biaryls
}

\author{
Juyoung Lee ${ }^{\dagger}$ Boseok Hong, ${ }^{\dagger}$ and Anna Lee*,†,
}

${ }^{\dagger}$ Department of Chemistry, ${ }^{ \pm}$Department of Energy Science and Technology, Myongi University, Yongin 17058, Republic of Korea

E-mail: annalee@mju.ac.kr

\section{Supporting Information}

\section{Table of Contents}

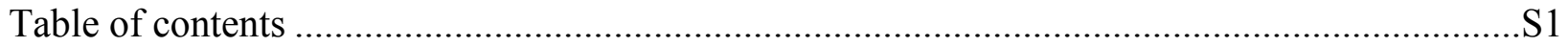

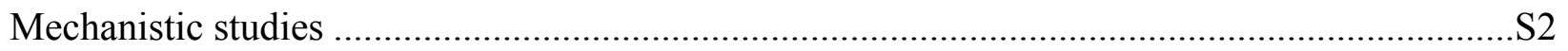

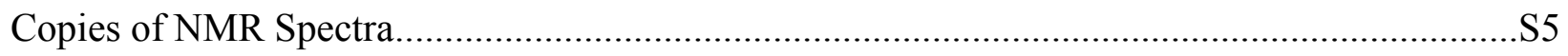




\section{Mechanistic studies}

\section{(1) Determination of the donor/acceptor ratio of $\mathrm{EDA}$ in $\mathrm{CH}_{3} \mathrm{CN}$}

The stoichiometry of the donor-acceptor complex was investigated by constructing a Job plot of the UV-vis spectroscopy results. Solutions of the donor (pyridine, $0.8 \mathrm{M}$ in $\mathrm{CH}_{3} \mathrm{CN}$ ) and the acceptor (4-methoxybenzenediazonium tetrafluoroborate, $0.8 \mathrm{M}$ in $\mathrm{CH}_{3} \mathrm{CN}$ ) were prepared and then mixed with the ratio of donor/acceptor from $0 \%$ to $100 \%$. All the absorption spectra were recorded in $1 \mathrm{~cm}$ path quartz cuvettes. Table $\mathrm{S} 1$ summarizes the observed absorption (Abs $\mathrm{EDA}_{\text {) }}$ associated to the variation of the donor/acceptor ratio at $405 \mathrm{~nm}$ of the EDA complex.

Table $\mathrm{S1}$ : Values of $\mathrm{Abs}(\mathrm{EDA})$ for $\mathrm{EDA}$ in $\mathrm{CH}_{3} \mathrm{CN}$ for different donor/acceptor ratios.

\begin{tabular}{|c|c|c|c|c|}
\hline $\begin{array}{c}\text { Ratio } \\
\text { acceptor/donor }\end{array}$ & (\% in pyridine) & $\begin{array}{c}\text { 4-methoxybenzene } \\
\text { diazonium salt }(\mathrm{M})\end{array}$ & pyridine (M) & Abs $_{\text {EDA }}$ \\
\hline $10 / 0$ & 0 & 0.8 & 0 & 0.43 \\
\hline $9 / 1$ & 10 & 0.72 & 0.08 & 1.51 \\
\hline $7 / 3$ & 30 & 0.56 & 0.24 & 1.71 \\
\hline $5 / 5$ & 50 & 0.4 & 0.4 & 1.77 \\
\hline $3 / 7$ & 70 & 0.24 & 0.72 & 0.53 \\
\hline $1 / 9$ & 90 & 0.08 & 0.8 & -0.01 \\
\hline $0 / 10$ & 100 & 0 & & 1.33 \\
\hline
\end{tabular}

From the above data, a symmetrical curve was obtained on plotting $\mathrm{Abs}_{\mathrm{EDA}} \mathrm{vs}$. the donor/acceptor ratio (Fig. S1). The maximum absorption is obtained for a 1:1 mixture of donor and acceptor, indicating that this is the stoichiometry of the EDA complex in solution. 


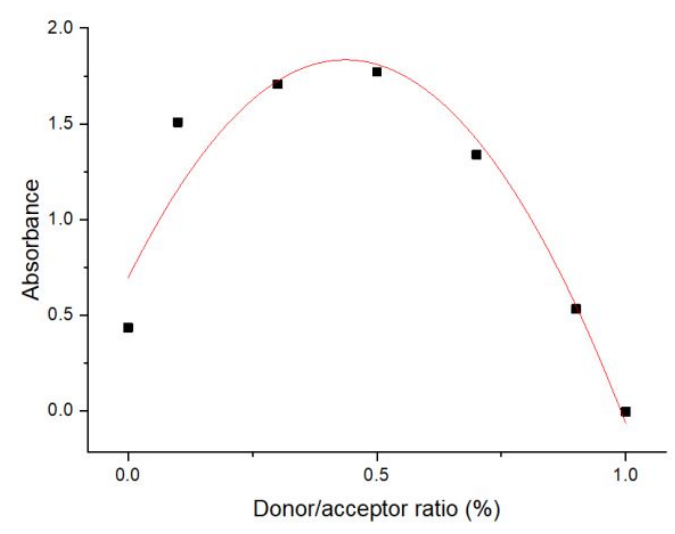

Figure S1: Job plot

\section{(2) Determination of the association constant ( $\left.K_{\mathrm{EDA}}\right)$}

The association constant of the EDA complex formed between aryl diazonium salt and pyridine was determined spectrophotometrically in $\mathrm{CH}_{3} \mathrm{CN}$, employing the Hildebrand-Benesi methodology. The absorption at $405 \mathrm{~nm}$ of solutions with constant concentration of the aryl diazonium salt $(0.1 \mathrm{M})$ and increased donor/acceptor ratio by adding an excess of pyridine was measured. All the absorption spectra were recorded in $1 \mathrm{~cm}$ path quartz cuvettes. Data obtained by UV-vis for EDA in $\mathrm{CH}_{3} \mathrm{CN}$ are shown in table $\mathrm{S} 2$.

Table S2: Data obtained by UV-vis for EDA in $\mathrm{CH}_{3} \mathrm{CN}$, with 4-methoxy benzene diazonium salt (0.1 M)

\begin{tabular}{|c|c|c|c|}
\hline pyridine $(\mathrm{M})$ & $1 /$ pyridine $\left(\mathrm{M}^{-1}\right)$ & $\mathrm{Abs}_{\mathrm{EDA}}$ & $1 /\left(\mathrm{Abs}_{\mathrm{EDA}}-\mathrm{A}_{0}\right)$ \\
\hline 0.1 & 10 & 0.681 & 1.662 \\
\hline 0.2 & 5 & 0.734 & 1.528 \\
\hline 0.3 & 3.33 & 0.829 & 1.335 \\
\hline 0.4 & 2.5 & 0.861 & 1.279 \\
\hline 0.5 & 2 & 0.906 & 1.210 \\
\hline 0.6 & 1.67 & 0.938 & 1.164 \\
\hline 0.7 & 1.43 & 0.957 & 1.139 \\
\hline
\end{tabular}


According to equation 1, a linear plot which is shown in Fig. S2 was obtained for this EDA system. $\left(\mathrm{A}_{0}=0.079, \mathrm{~A}\right.$ : the absorption in the absence and presence of pyridine, $\mathrm{A}_{\max }$ : the maximum absorption in the presence of pyridine, $\mathrm{K}_{\mathrm{EDA}}$ : equilibrium constant, $\mathrm{n}=1$, the stoichiometry of the EDA complex)

The equilibrium constant $\mathrm{K}_{\mathrm{EDA}}\left(\mathrm{K}_{\mathrm{EDA}}=1.1041 / 0.0613=18.01\right)$ was readily obtained from the slope of these plots.

$$
\frac{1}{\mathrm{~A}-\mathrm{A} 0}=\frac{1}{\mathrm{Amax}-\mathrm{A} 0}\left(\frac{1}{\mathrm{KEDA}[\mathrm{NMM}] \mathrm{n}}+1\right)
$$

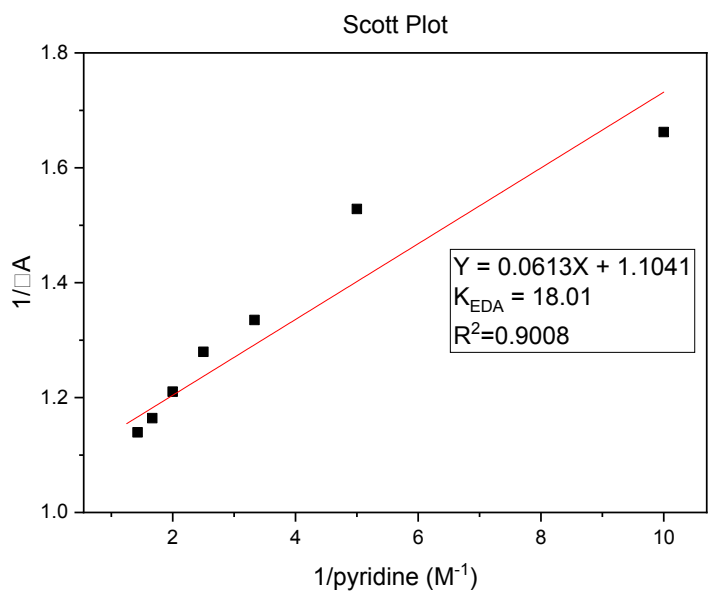

Figure S2: Scott plots 


\section{NMR Spectra}
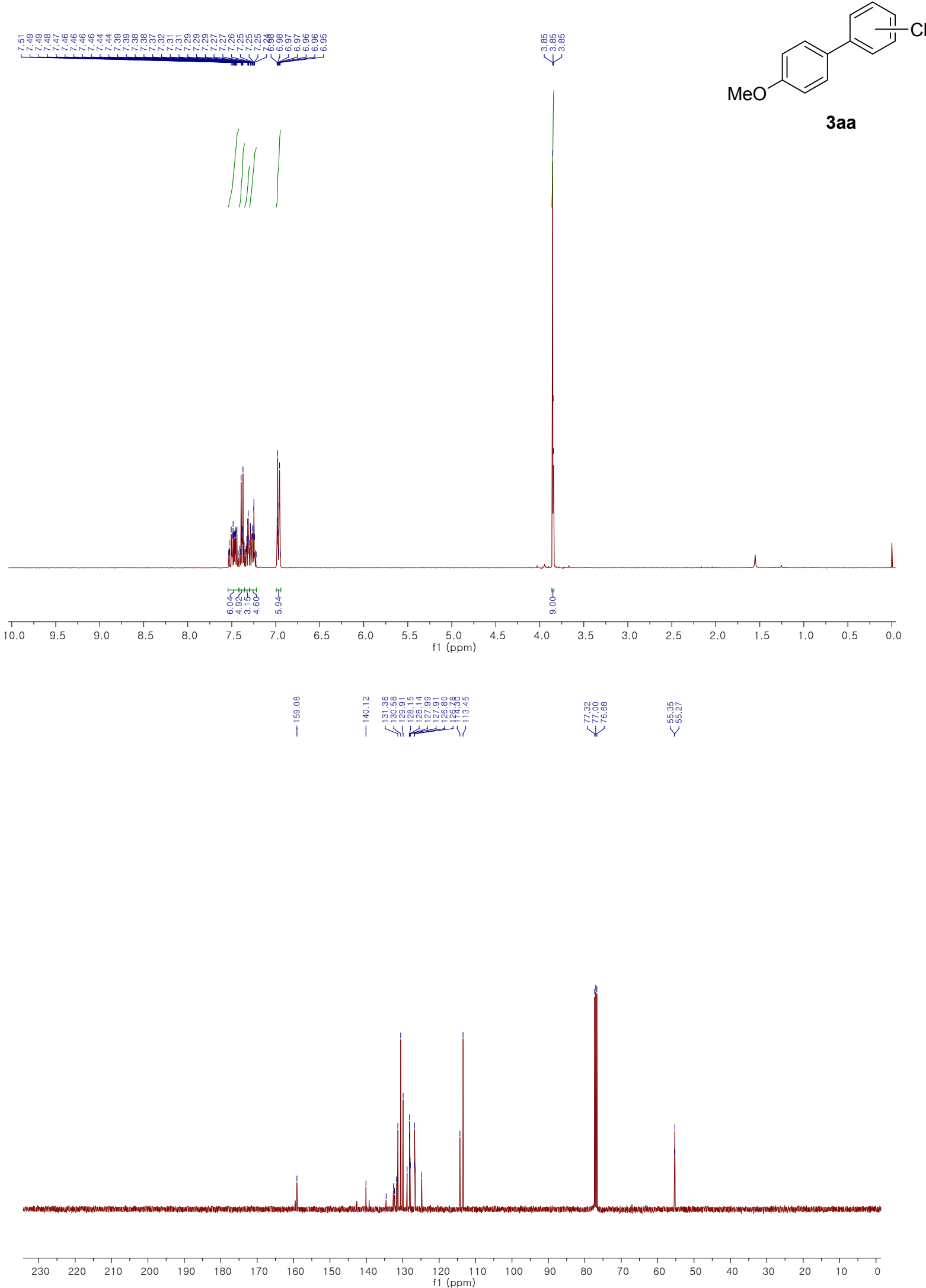


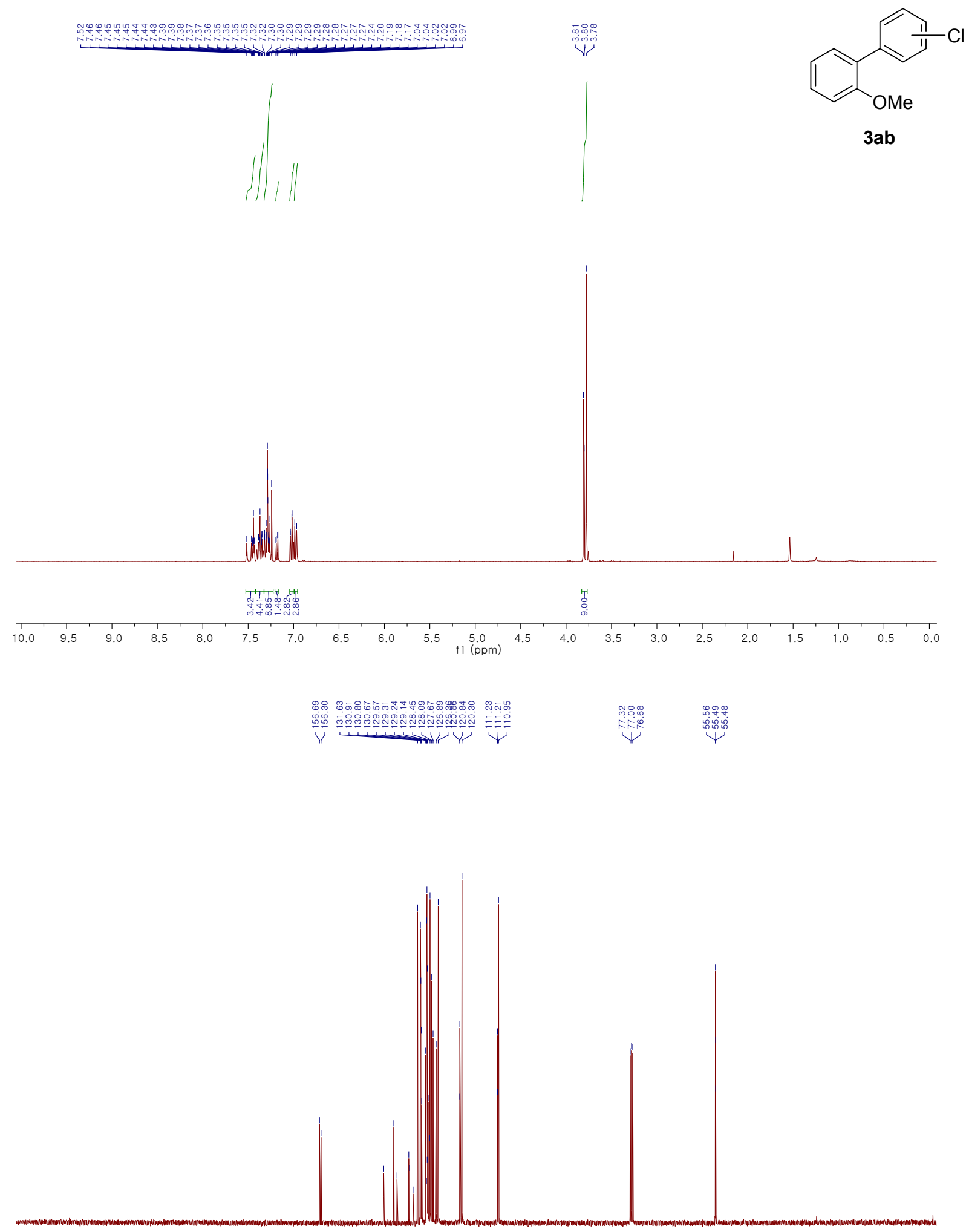

$\begin{array}{lllllllllllllllllllllllll}\mid & 230 & 220 & 210 & 200 & 190 & 180 & 170 & 160 & 150 & 140 & 130 & \begin{array}{c}120 \\ f 1\end{array}(\mathrm{ppm}) & 110 & 90 & 80 & 70 & 60 & 50 & 40 & 30 & 20 & 10 & 0\end{array}$ 


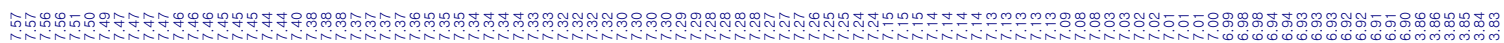
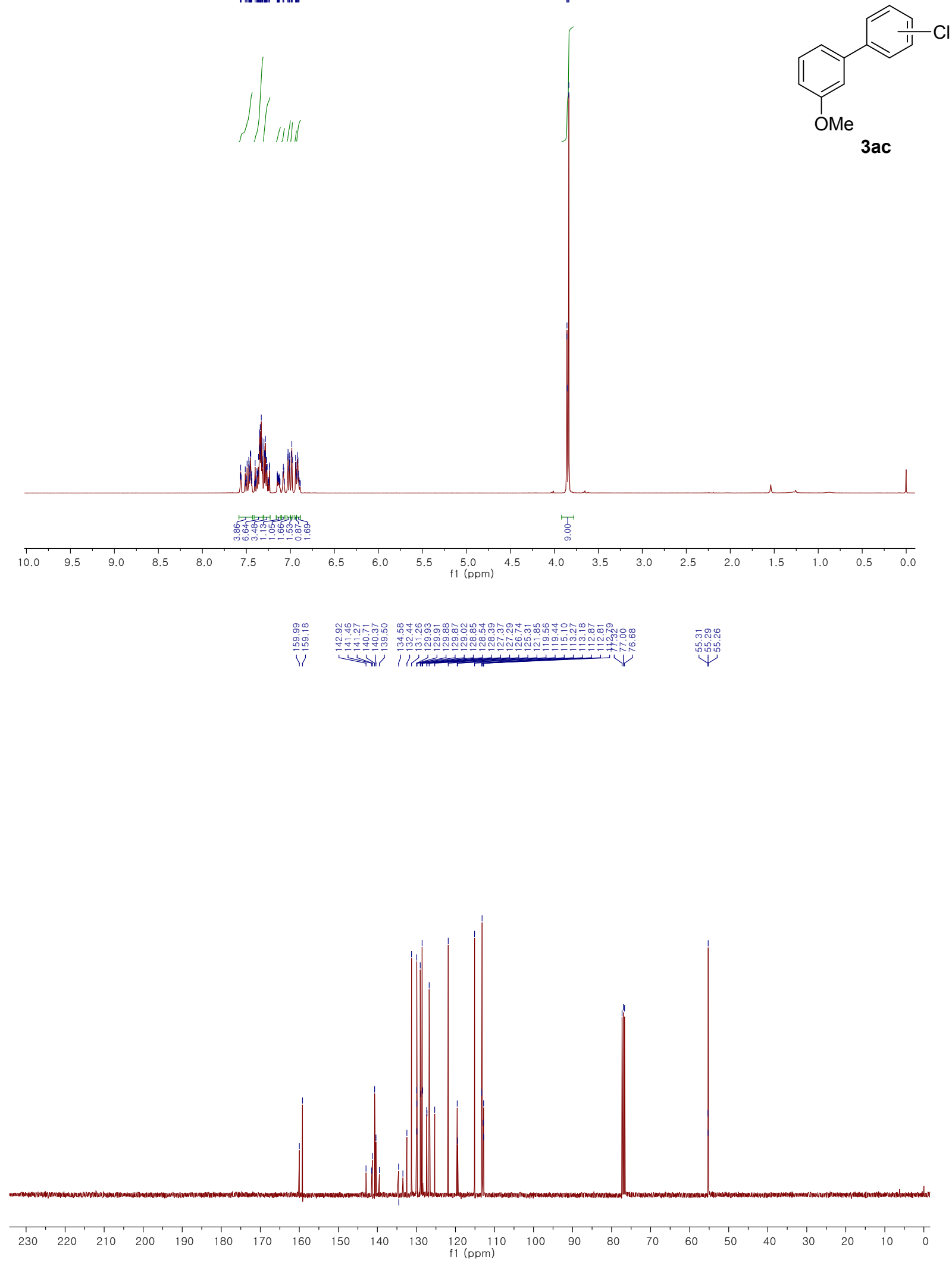


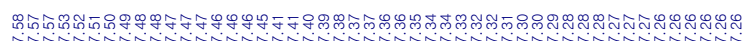
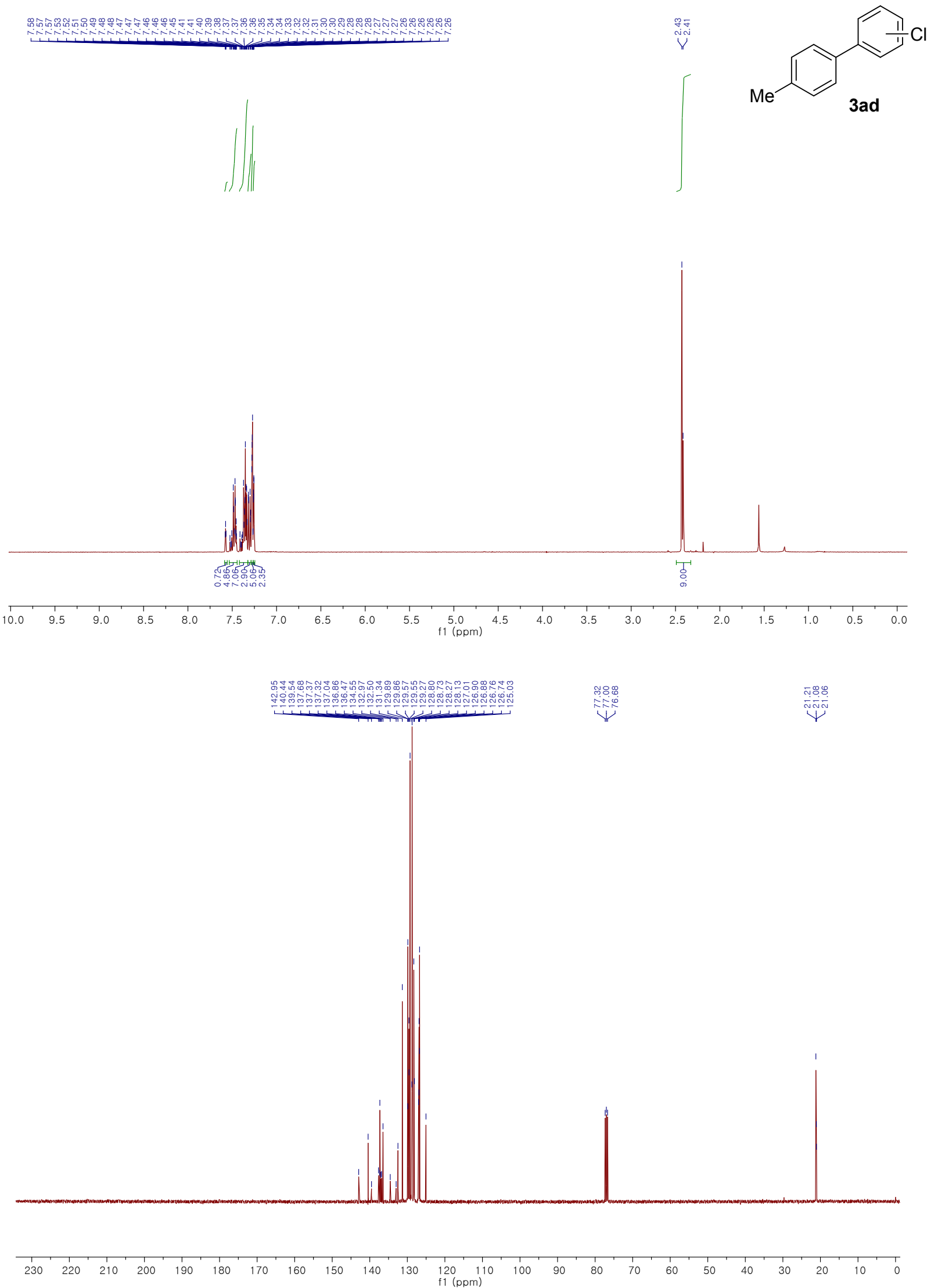
으웅요

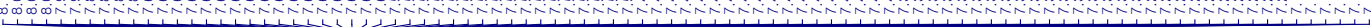

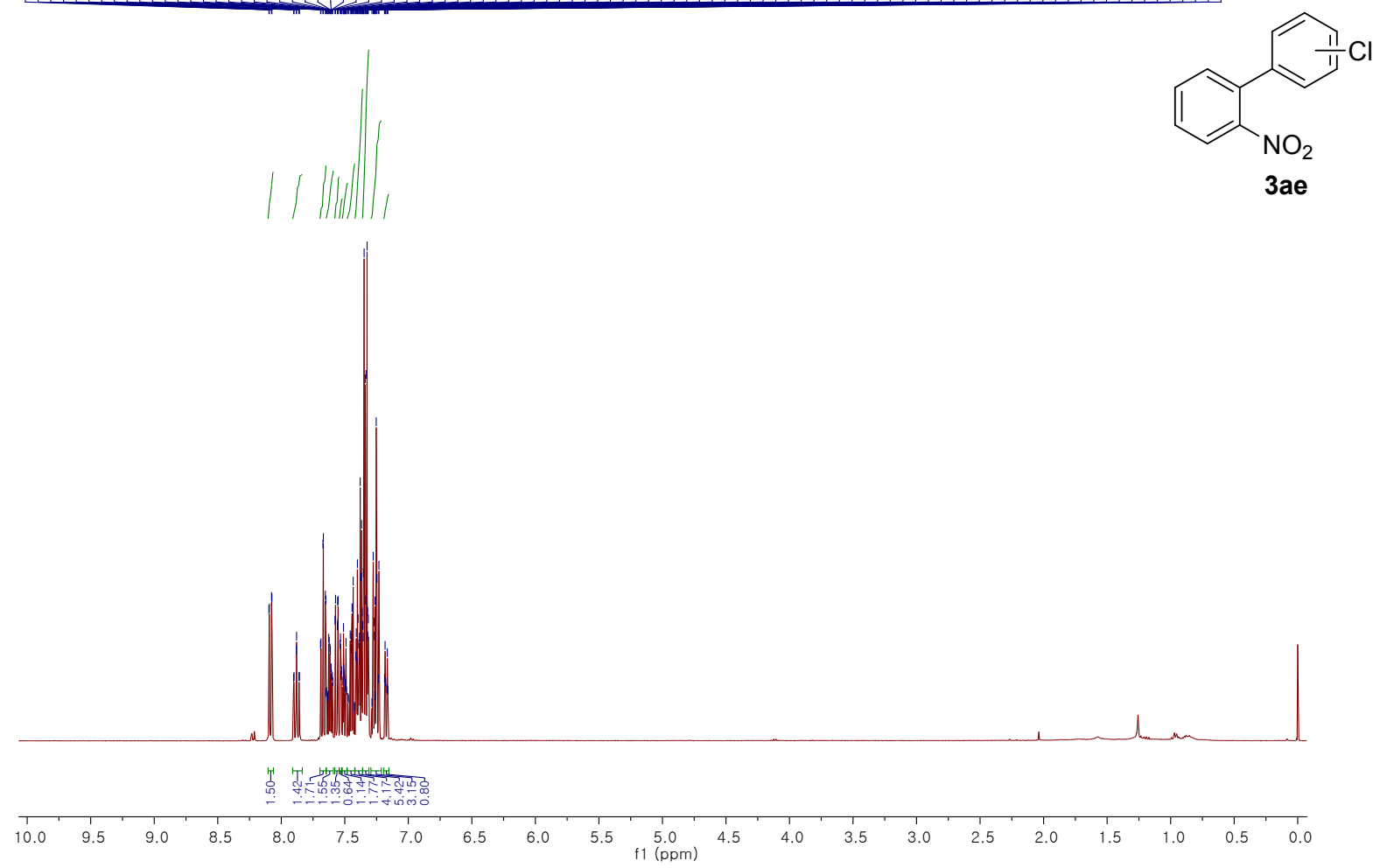

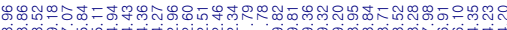

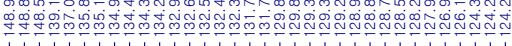

Y

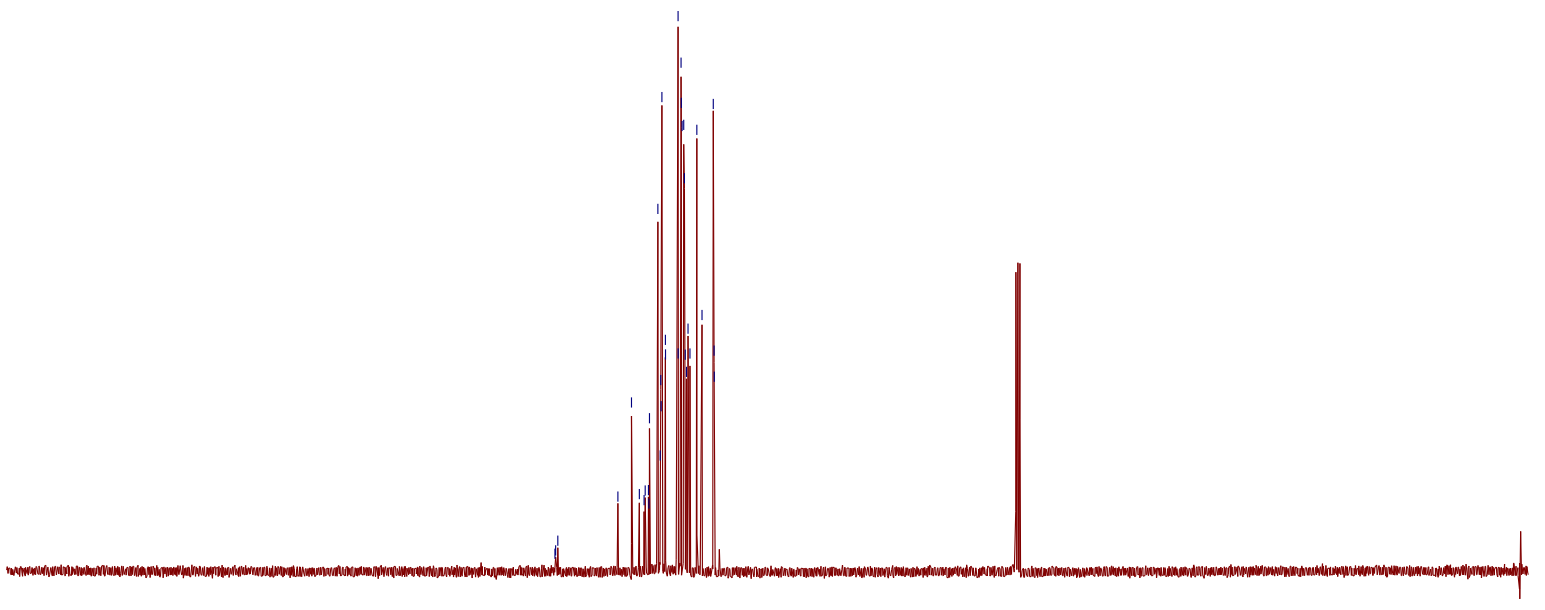

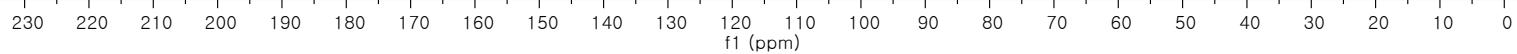




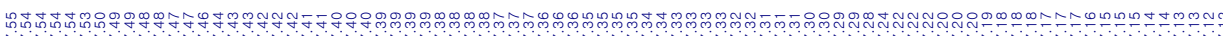

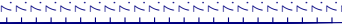
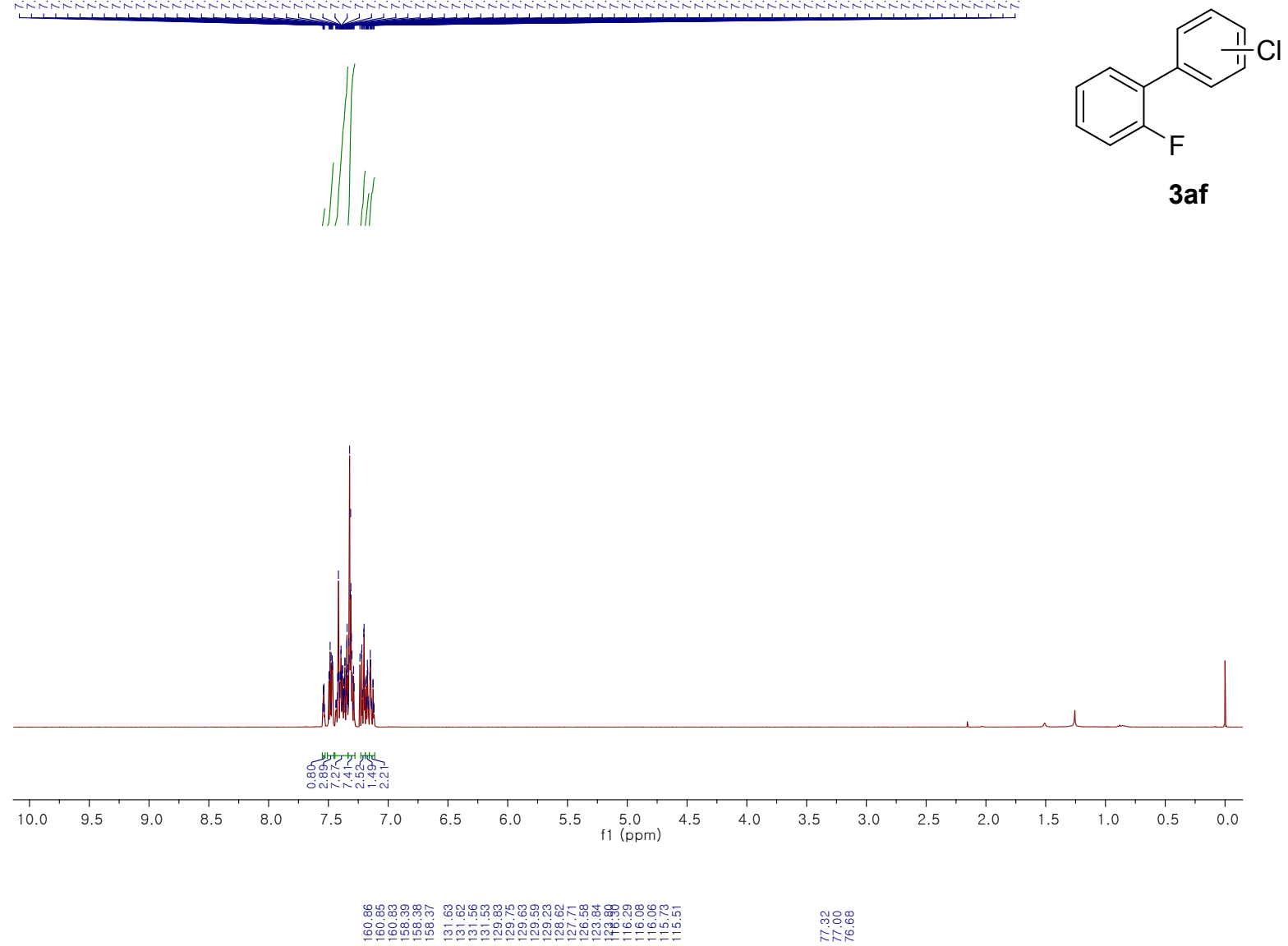

年

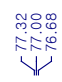

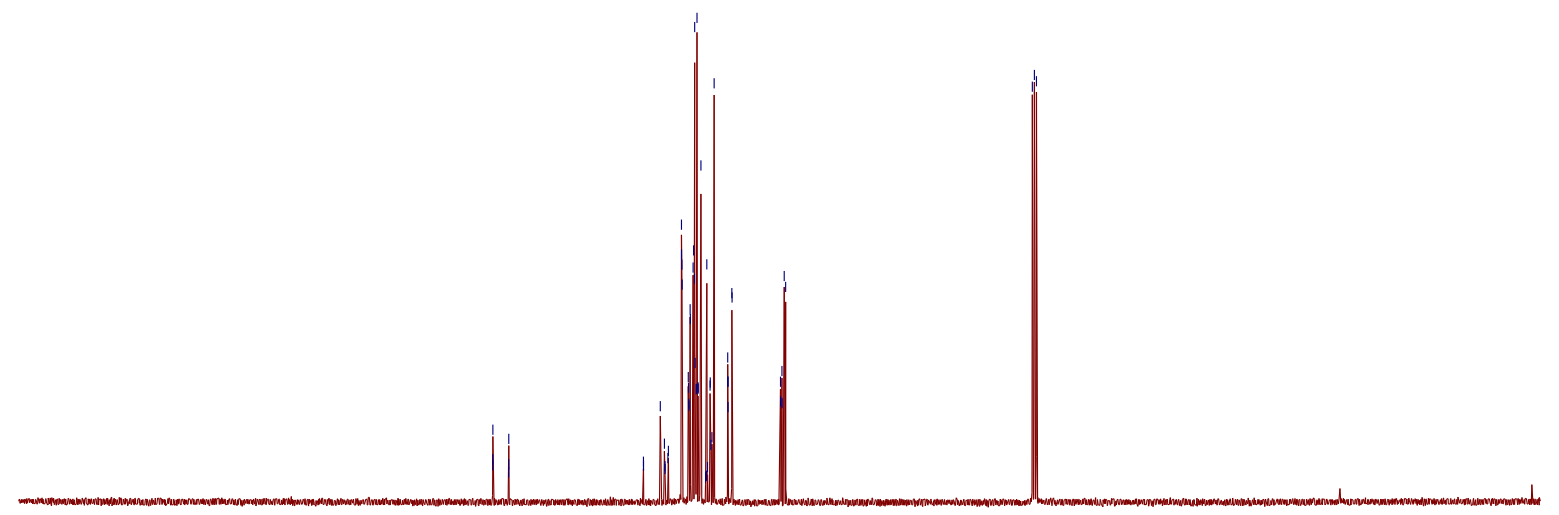

$\begin{array}{llllllllllllllllllllllllll} & 230 & 220 & 210 & 200 & 190 & 180 & 170 & 160 & 150 & 140 & 130 & \begin{array}{l}120 \\ \mathrm{f} 1(\mathrm{ppm})\end{array} & 110 & 90 & 80 & 70 & 60 & 50 & 40 & 30 & 20 & 10 & 0\end{array}$ 

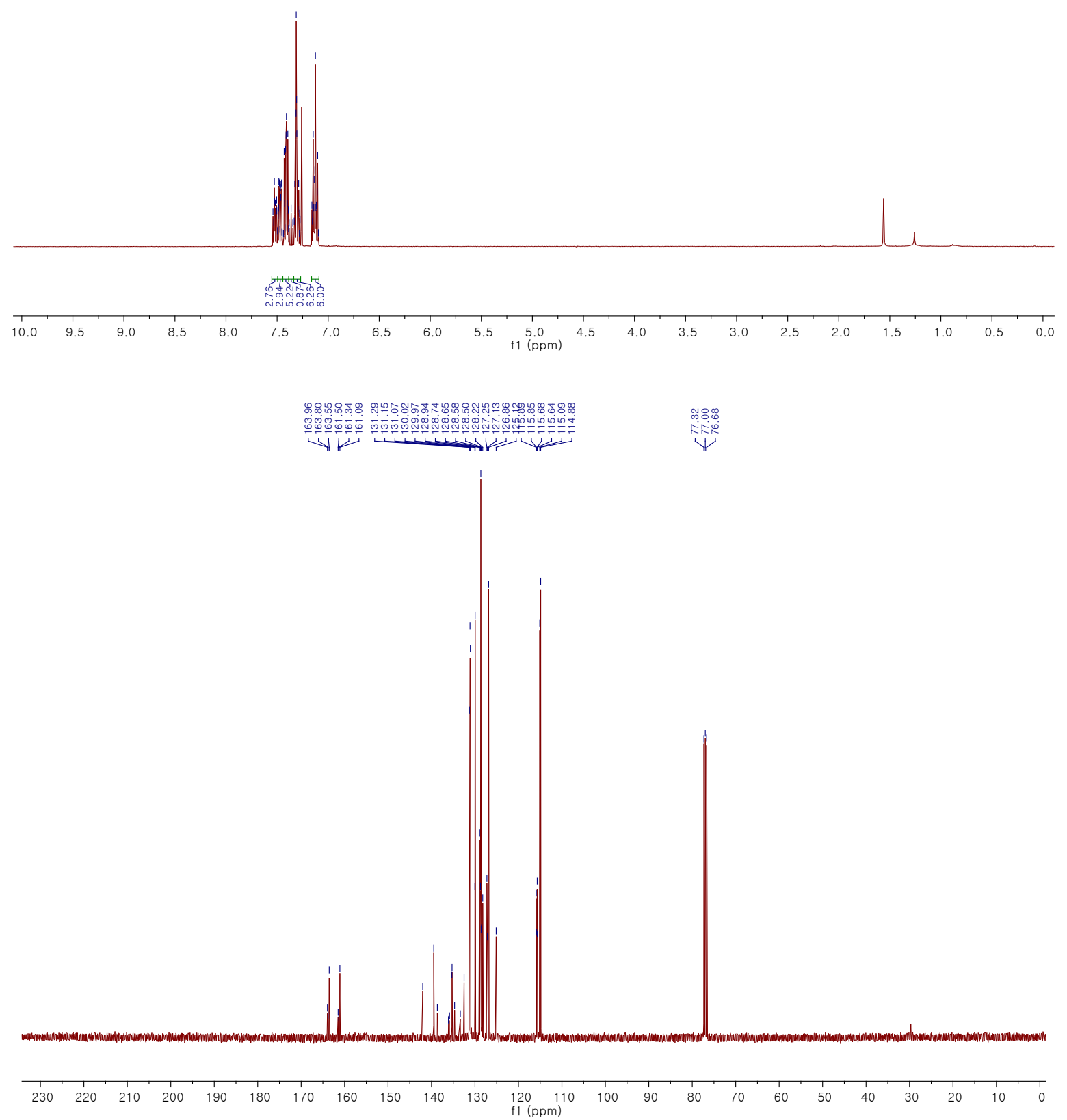


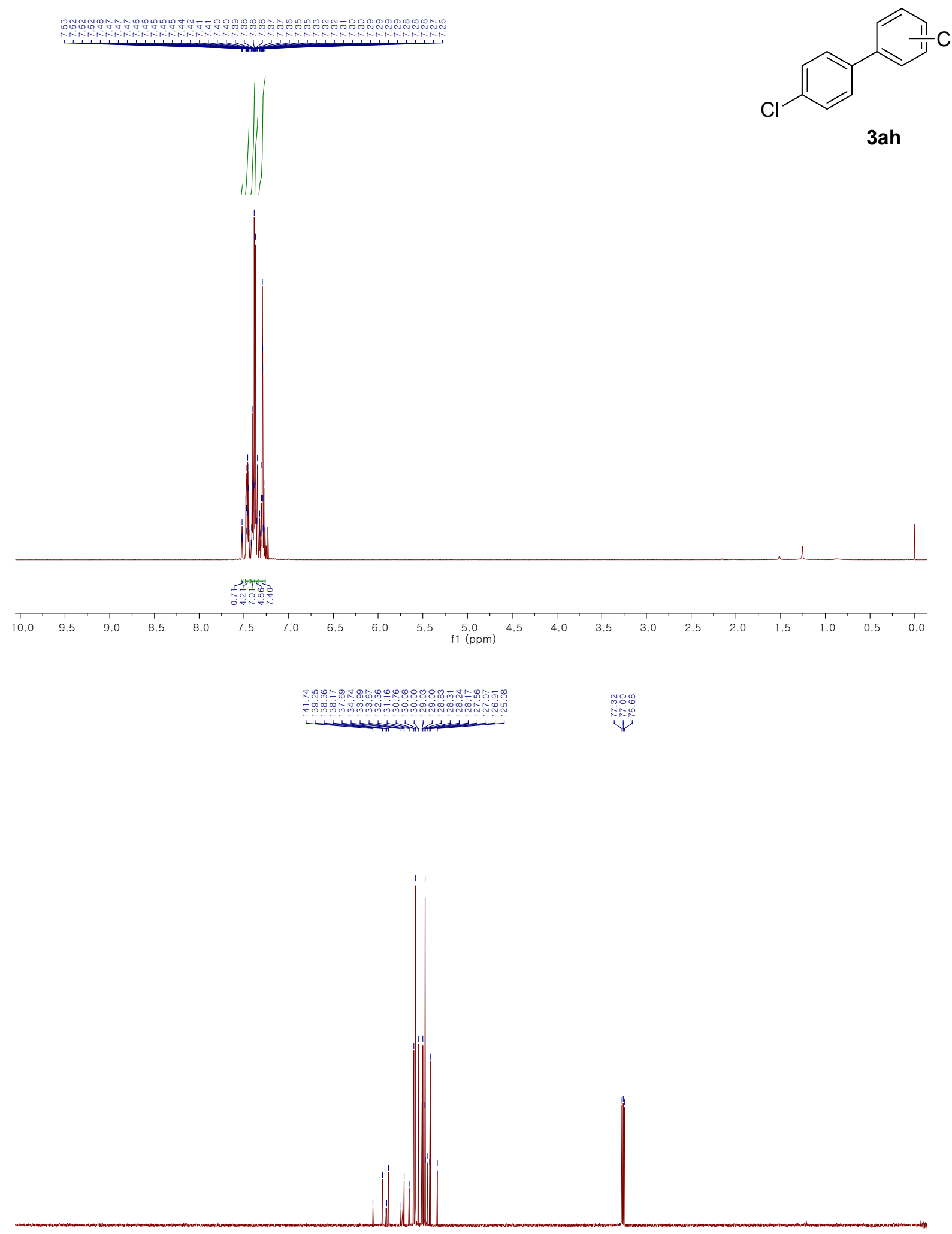

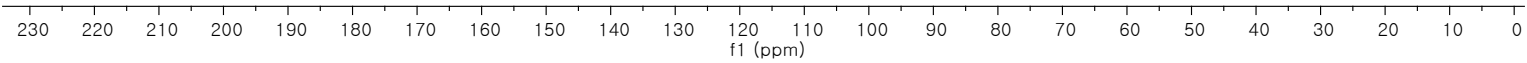




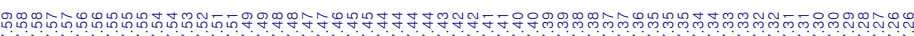
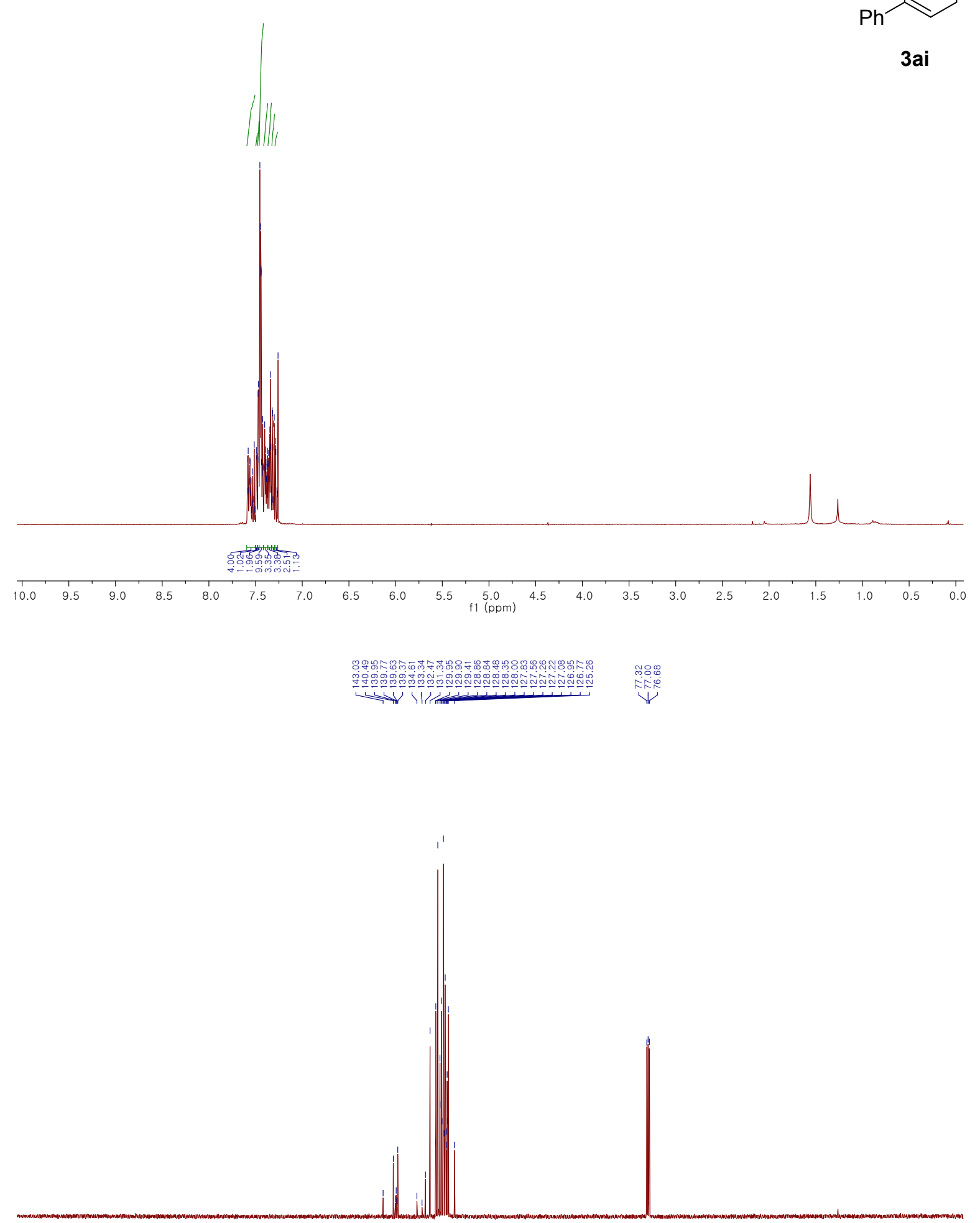

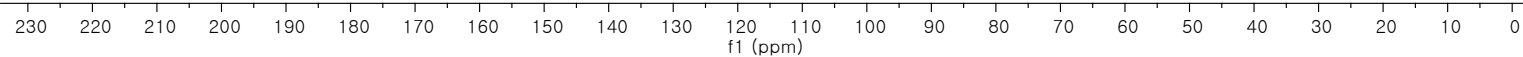




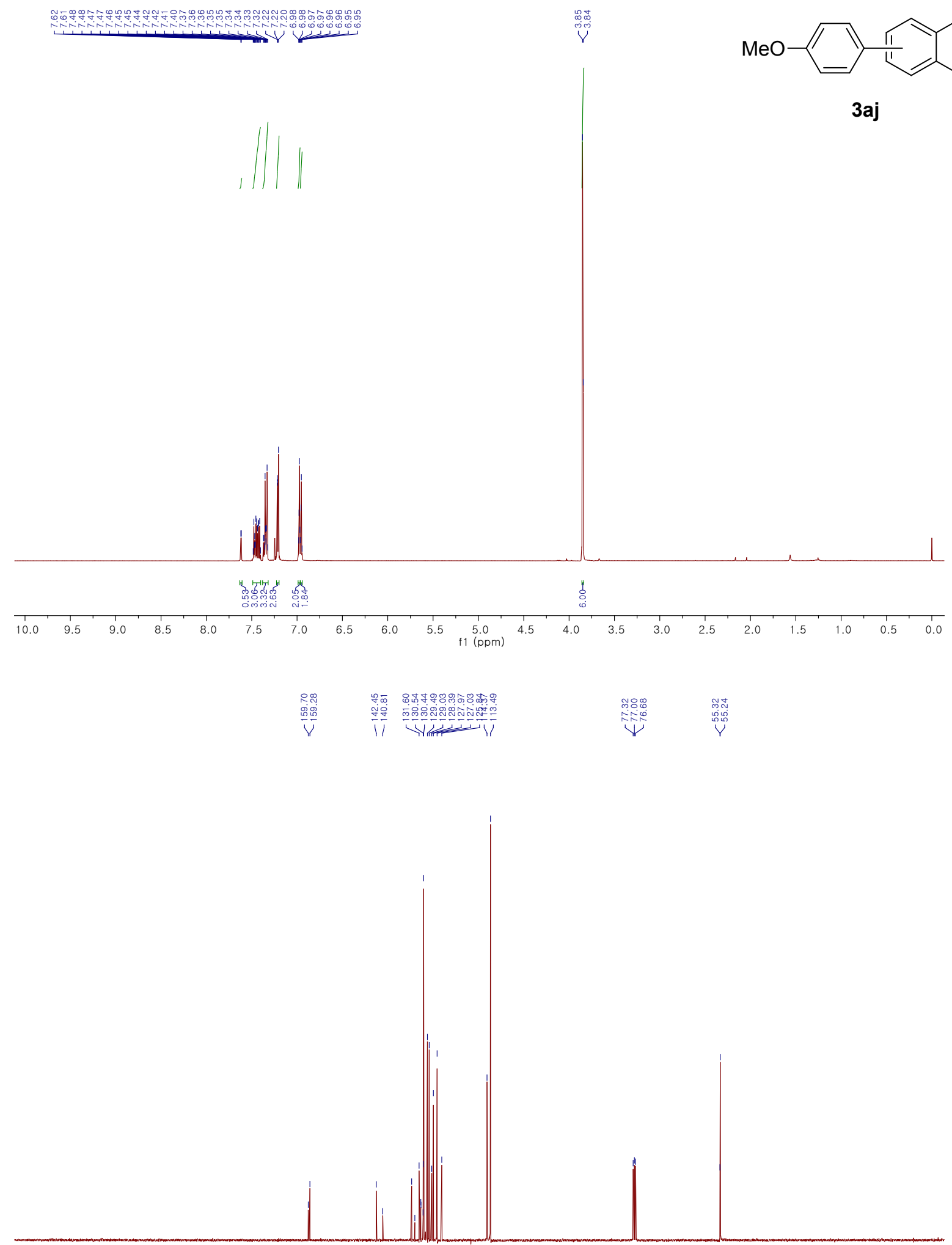

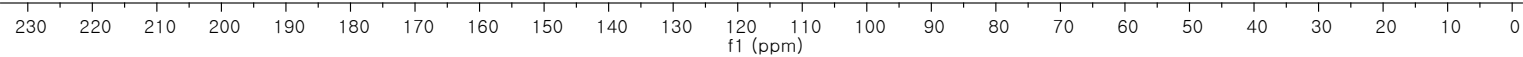



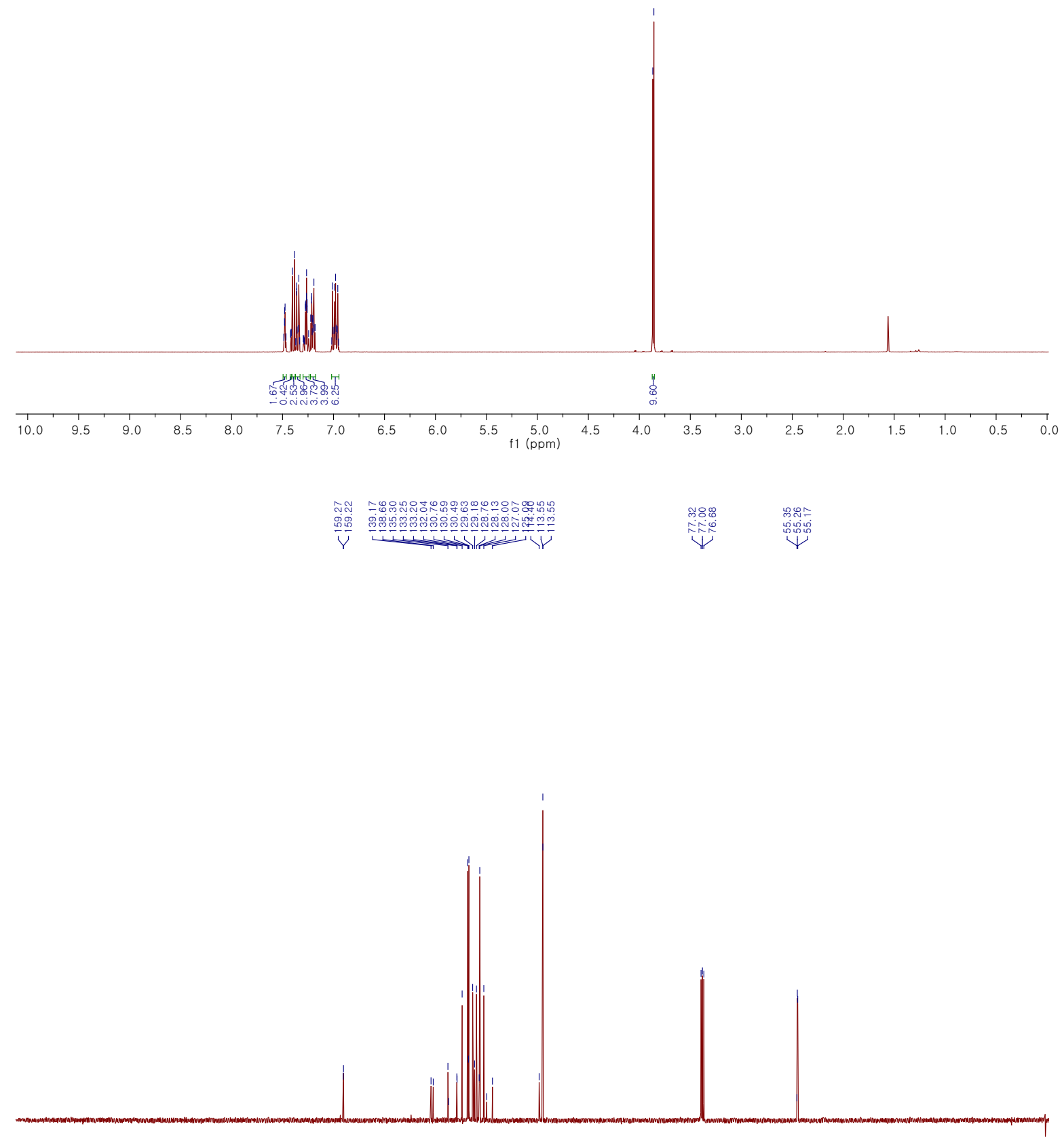

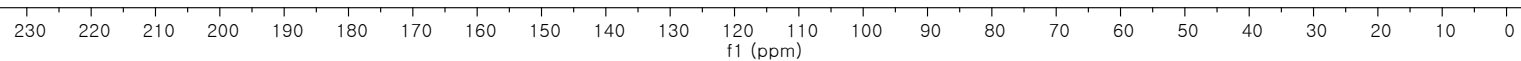




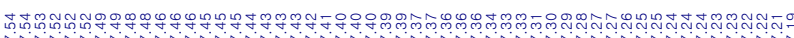

inivision

||

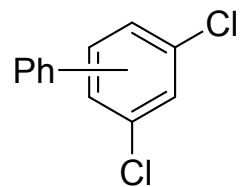

3al

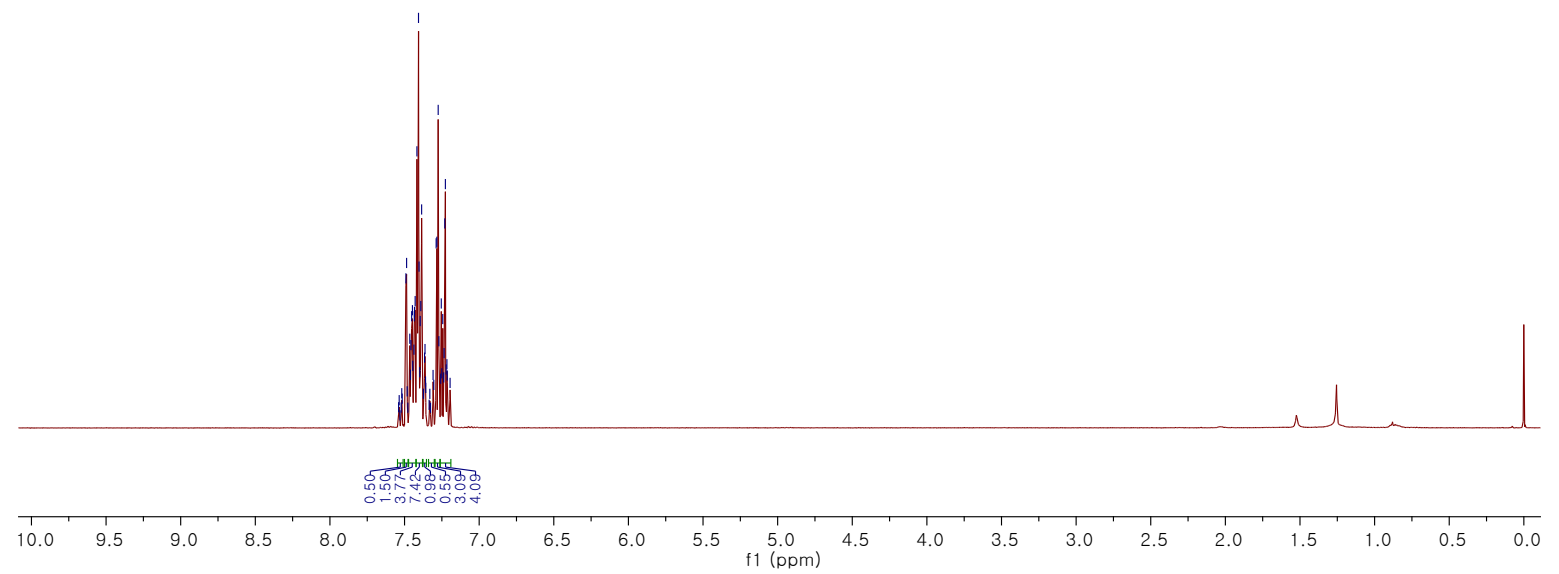

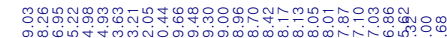
ming

i/1)

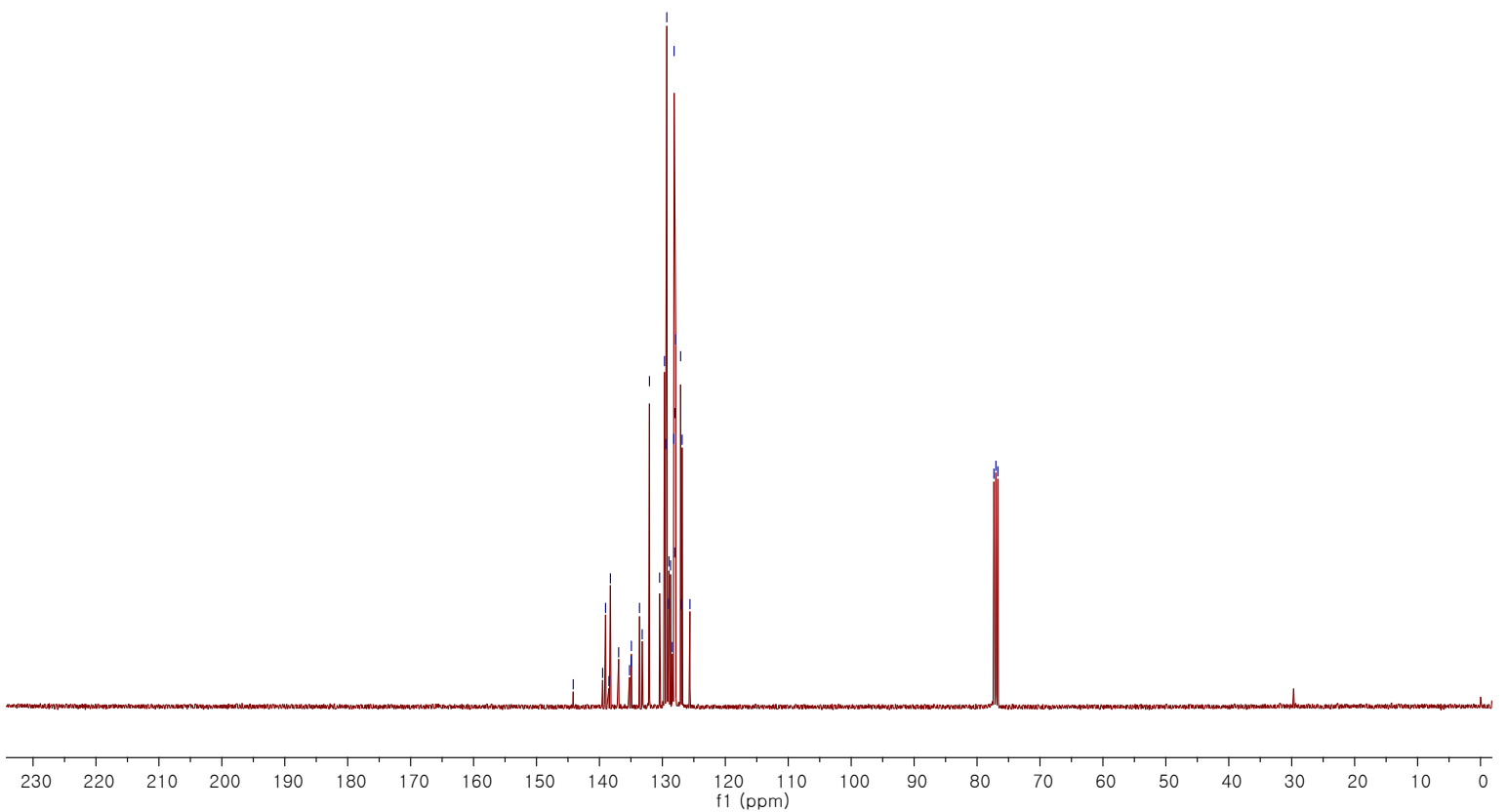



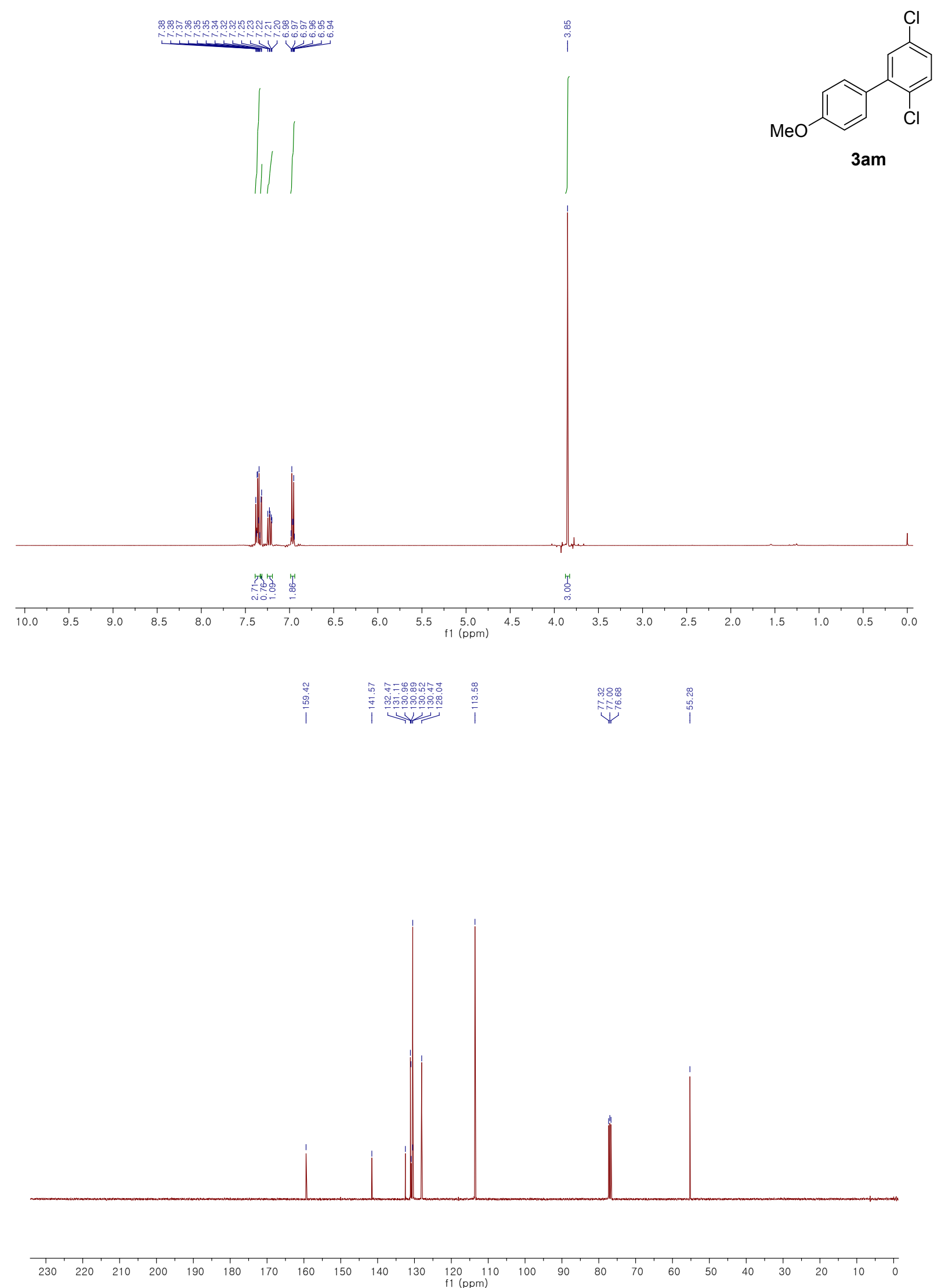


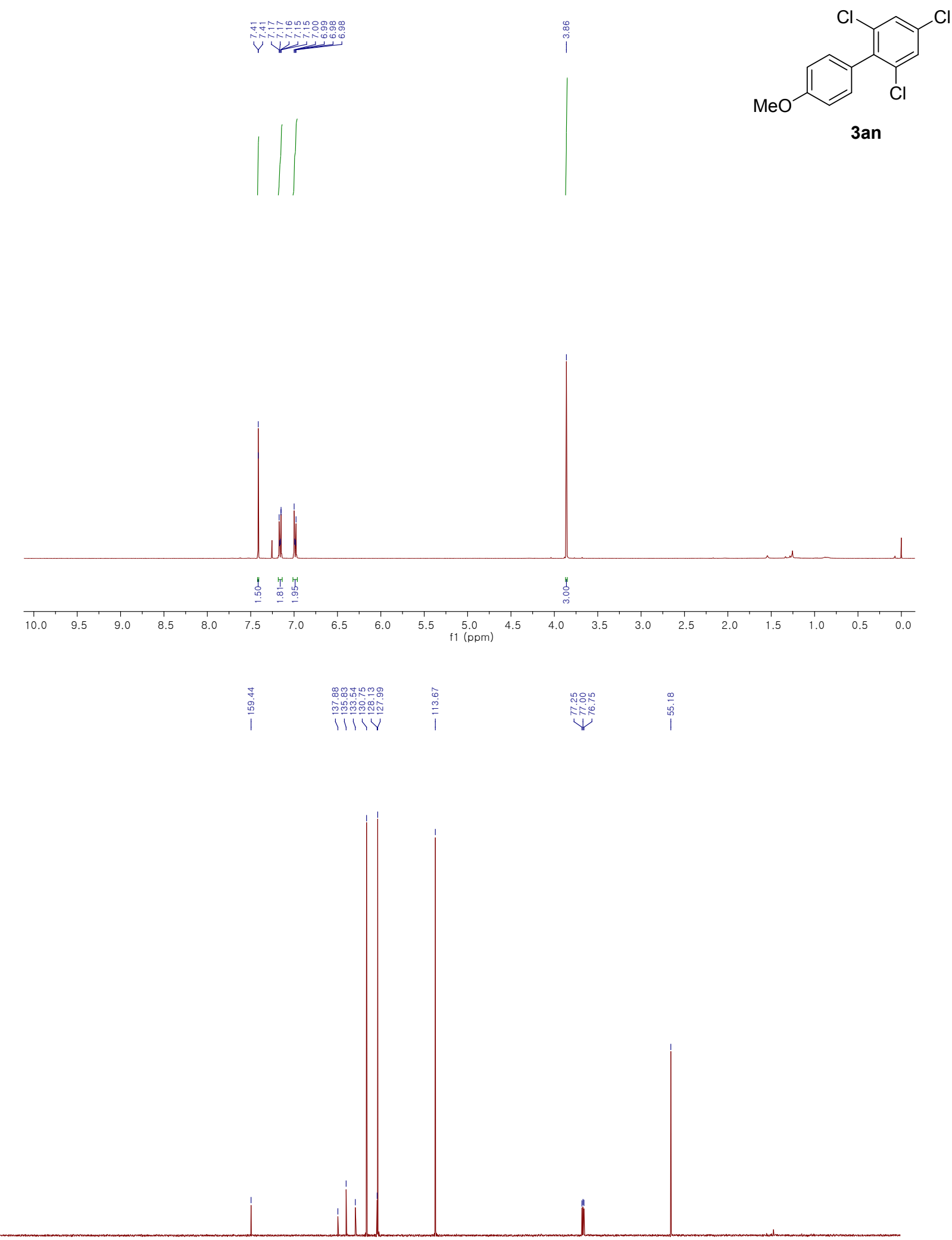

\begin{tabular}{llllllllllllllllllllllll}
\hline 1 & 220 & 210 & 200 & 190 & 180 & 170 & 160 & 150 & 140 & 130 & 120 & 110 & 100 & 90 & 80 & 70 & 60 & 50 & 40 & 30 & 20 & 10 & 0
\end{tabular} 

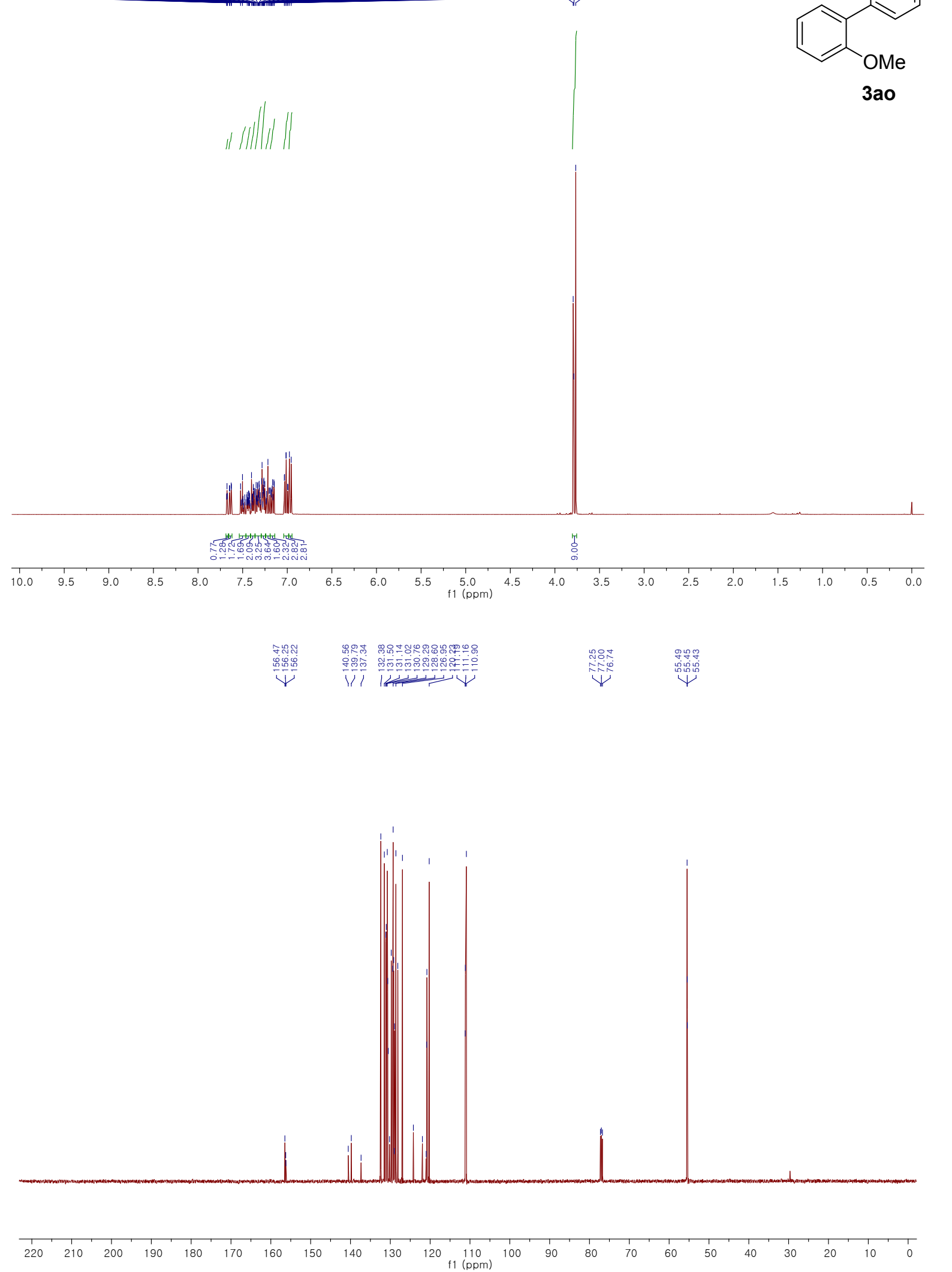

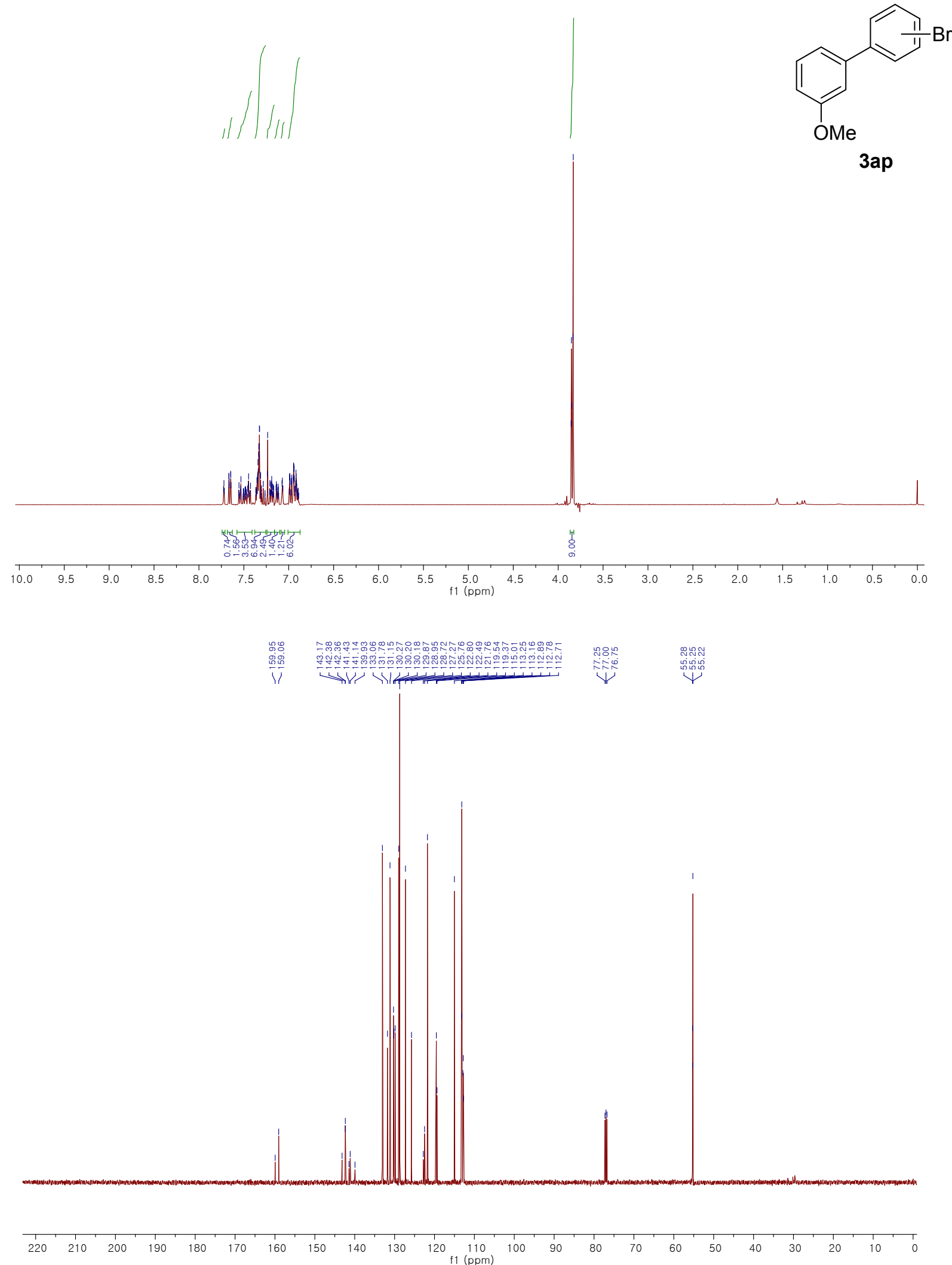


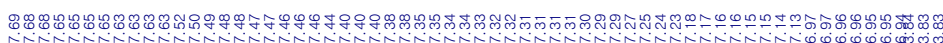
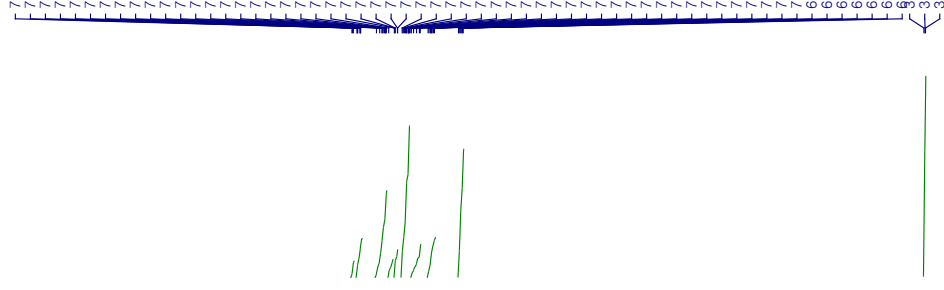

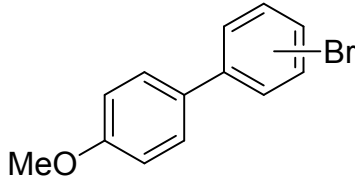

$3 a q$

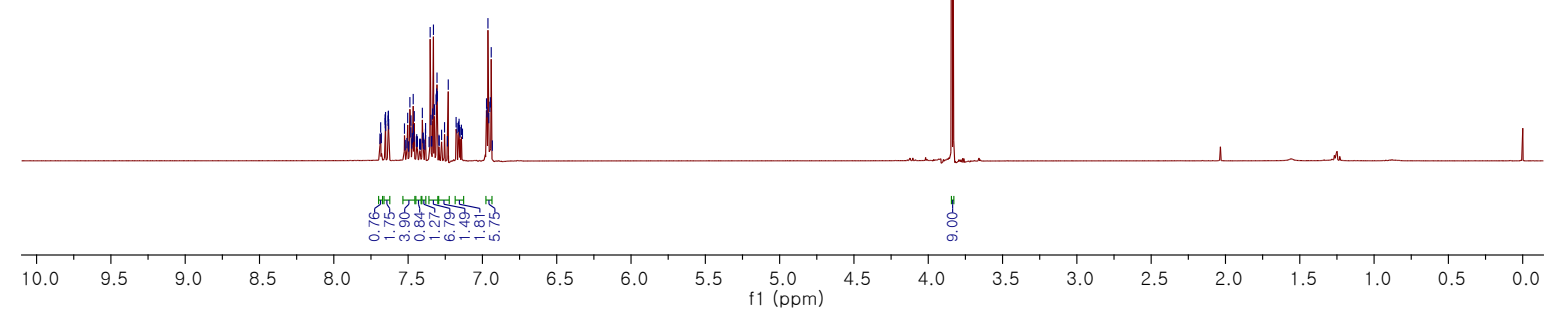

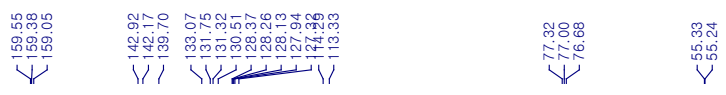
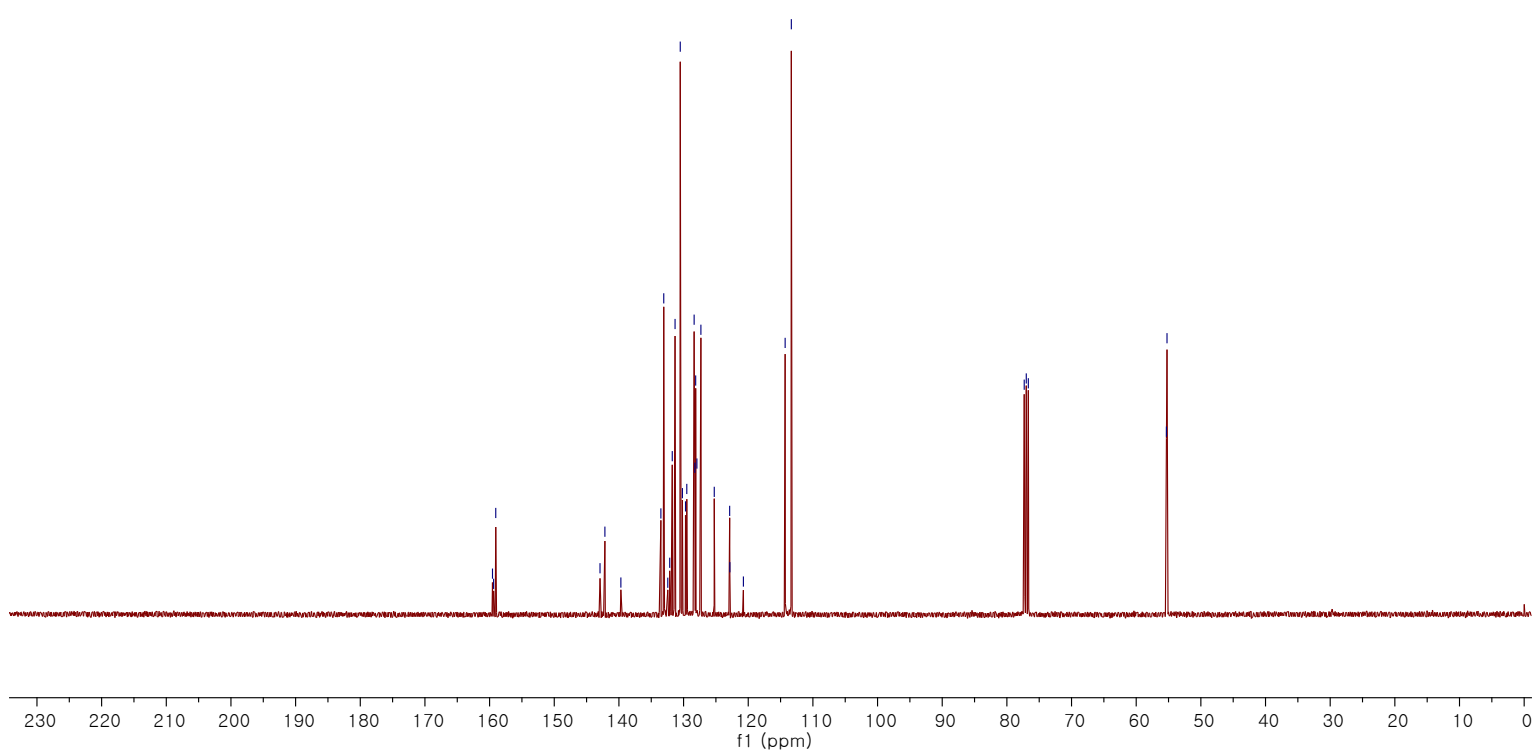

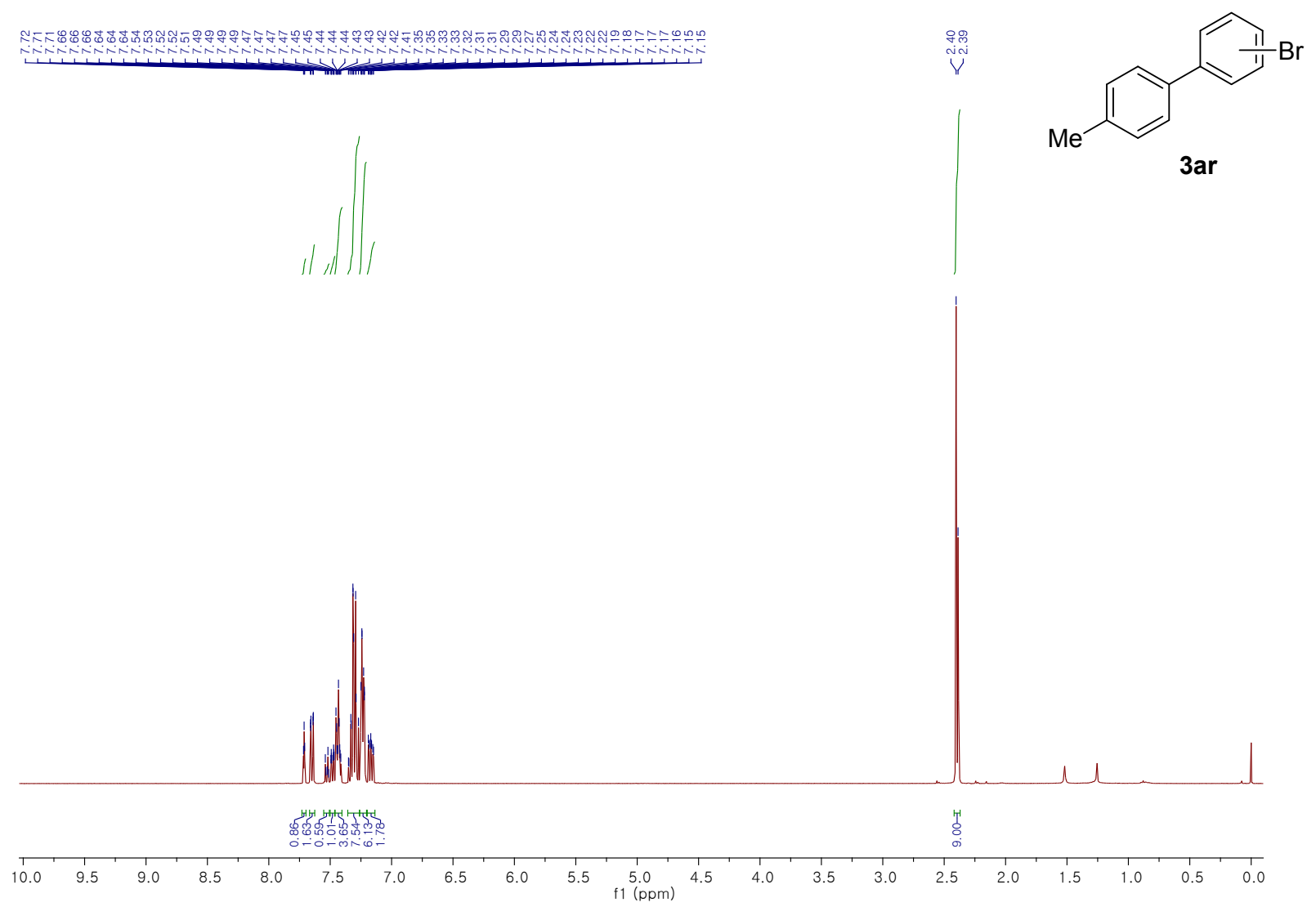

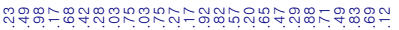

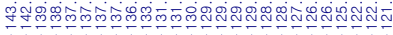

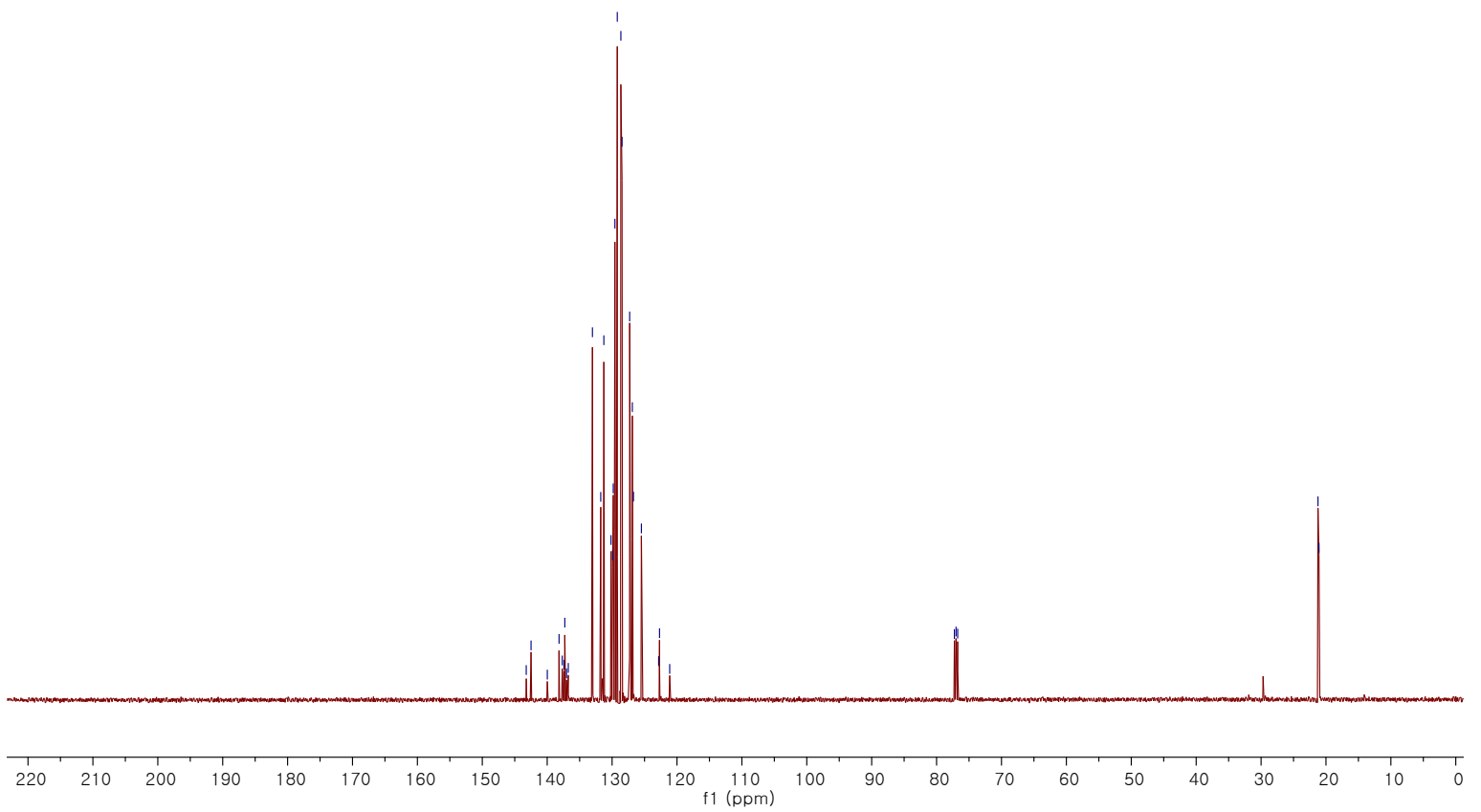




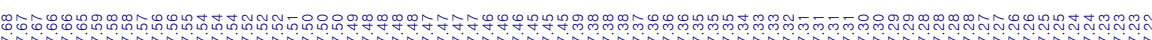

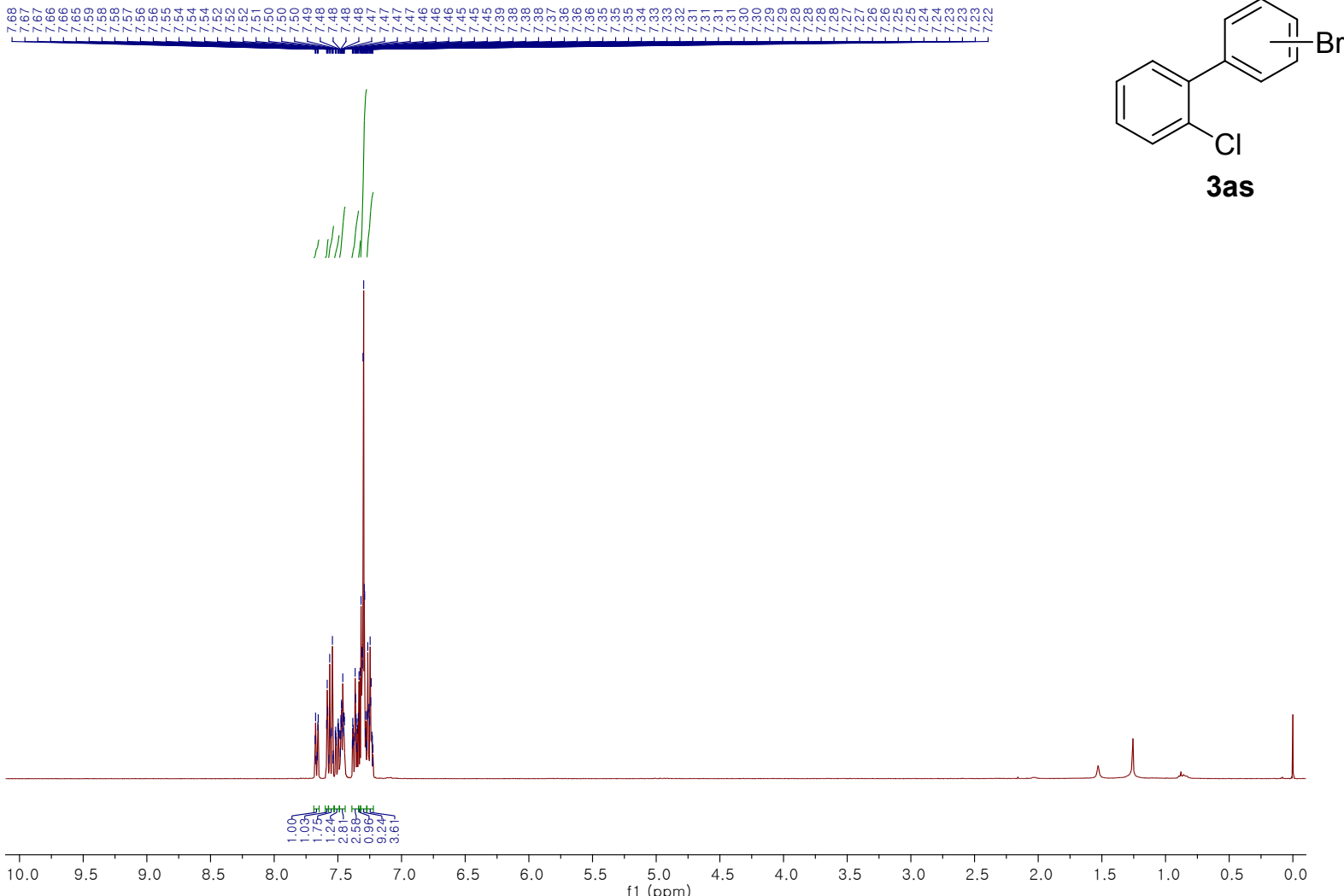

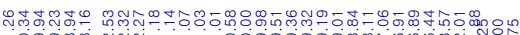

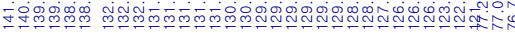

新/ /

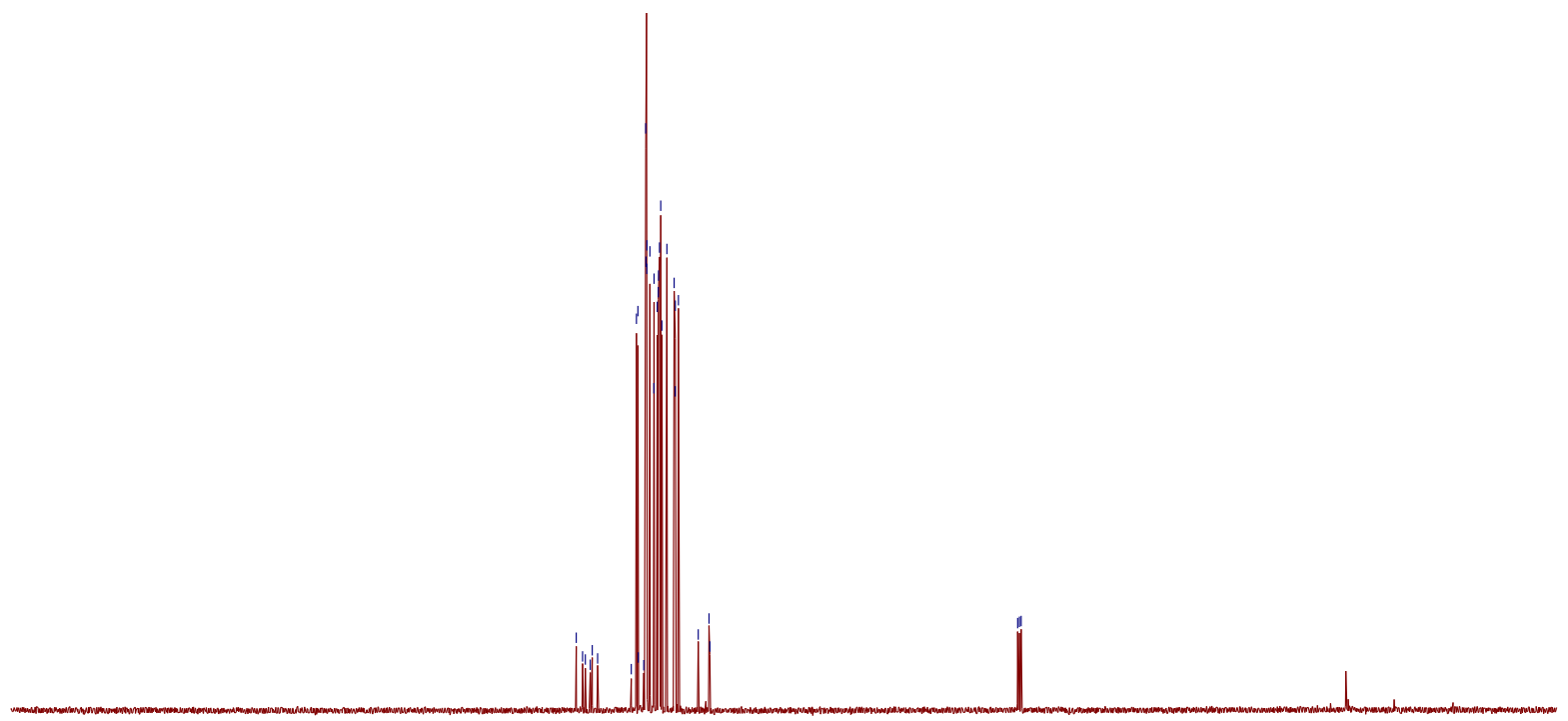

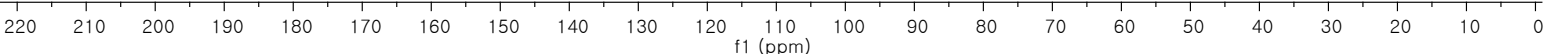




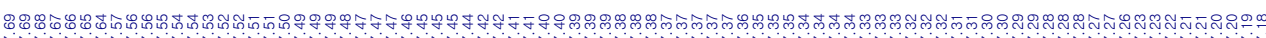

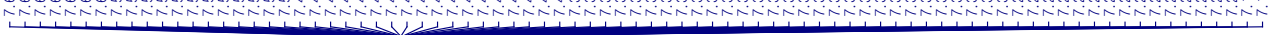
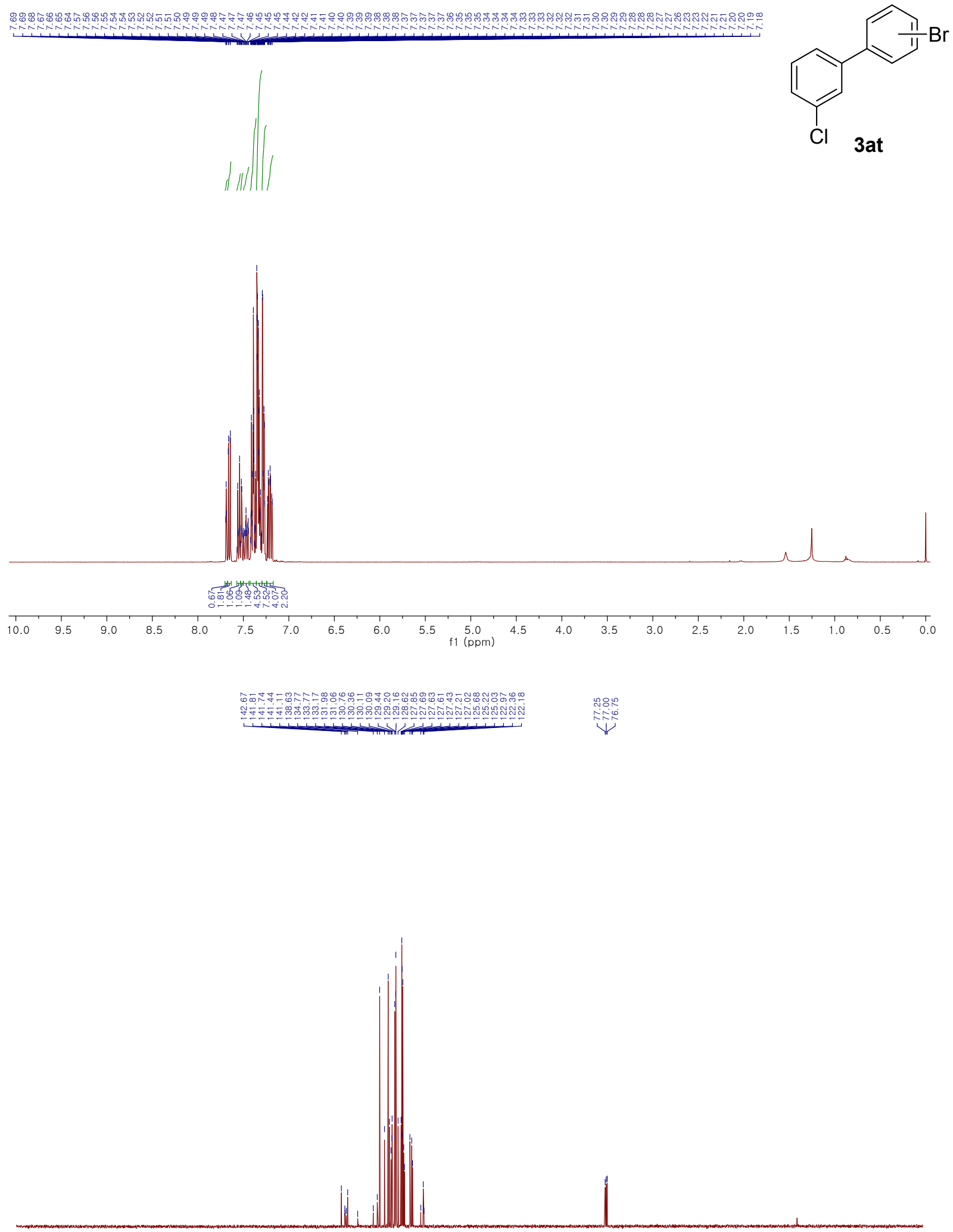


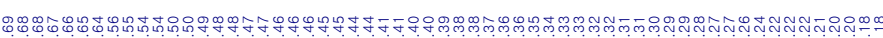

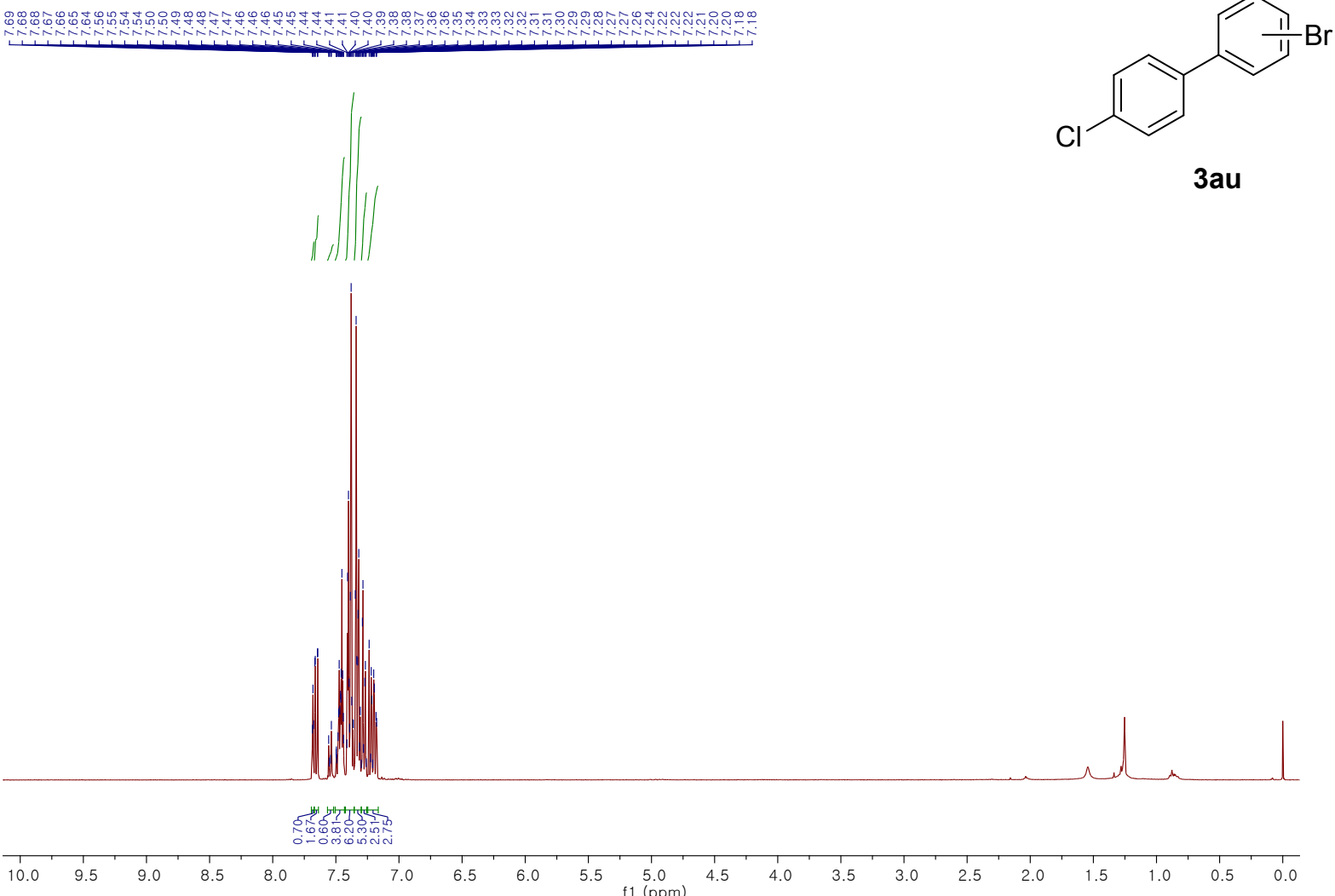

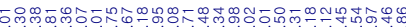

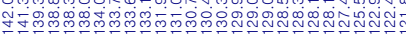

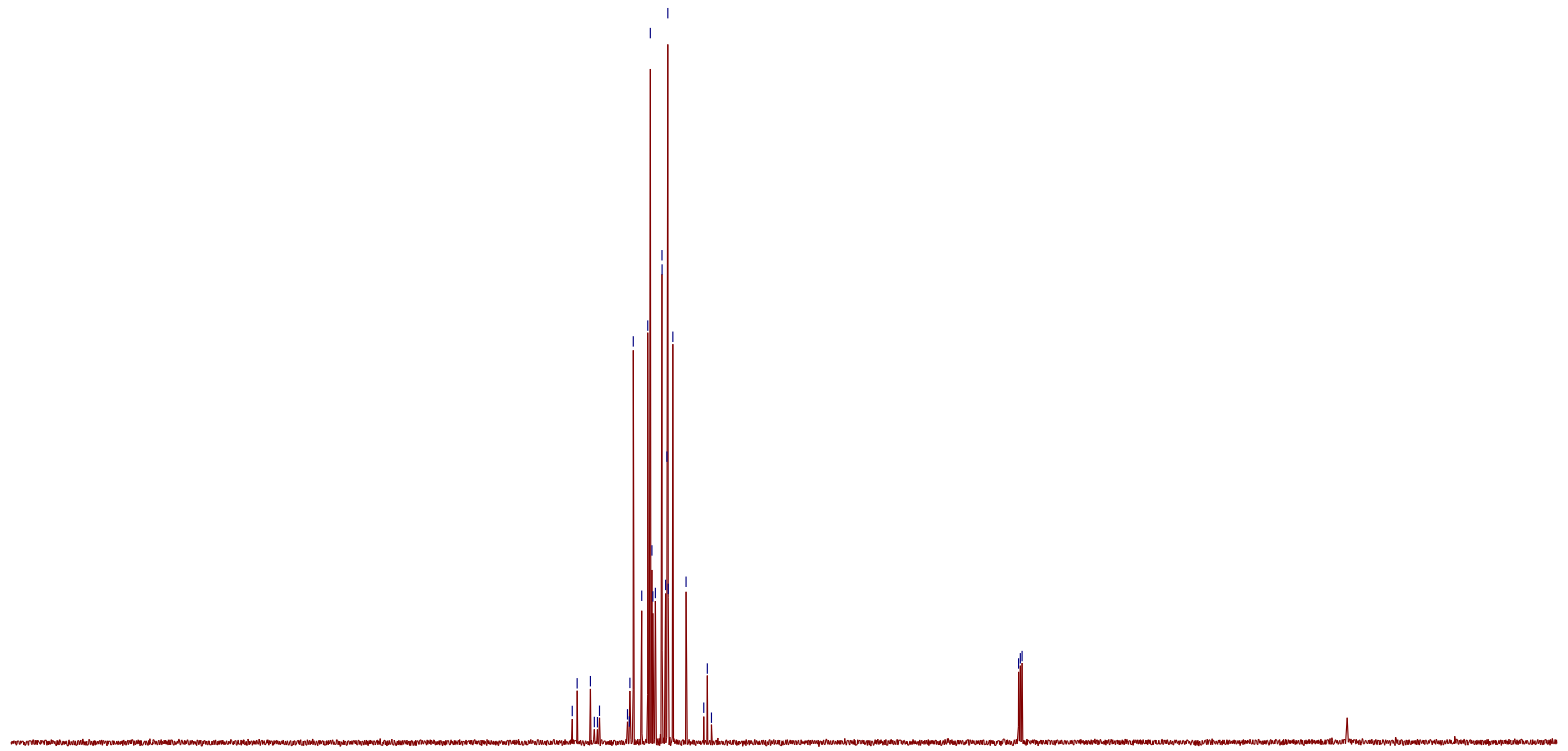

\begin{tabular}{lllllllllllllllllllllllll}
\hline & 220 & 210 & 200 & 190 & 180 & 170 & 160 & 150 & 140 & 130 & 120 & 110 & 100 & 90 & 80 & 70 & 60 & 50 & 40 & 30 & 20 & 10 & 0
\end{tabular} 
ஜ
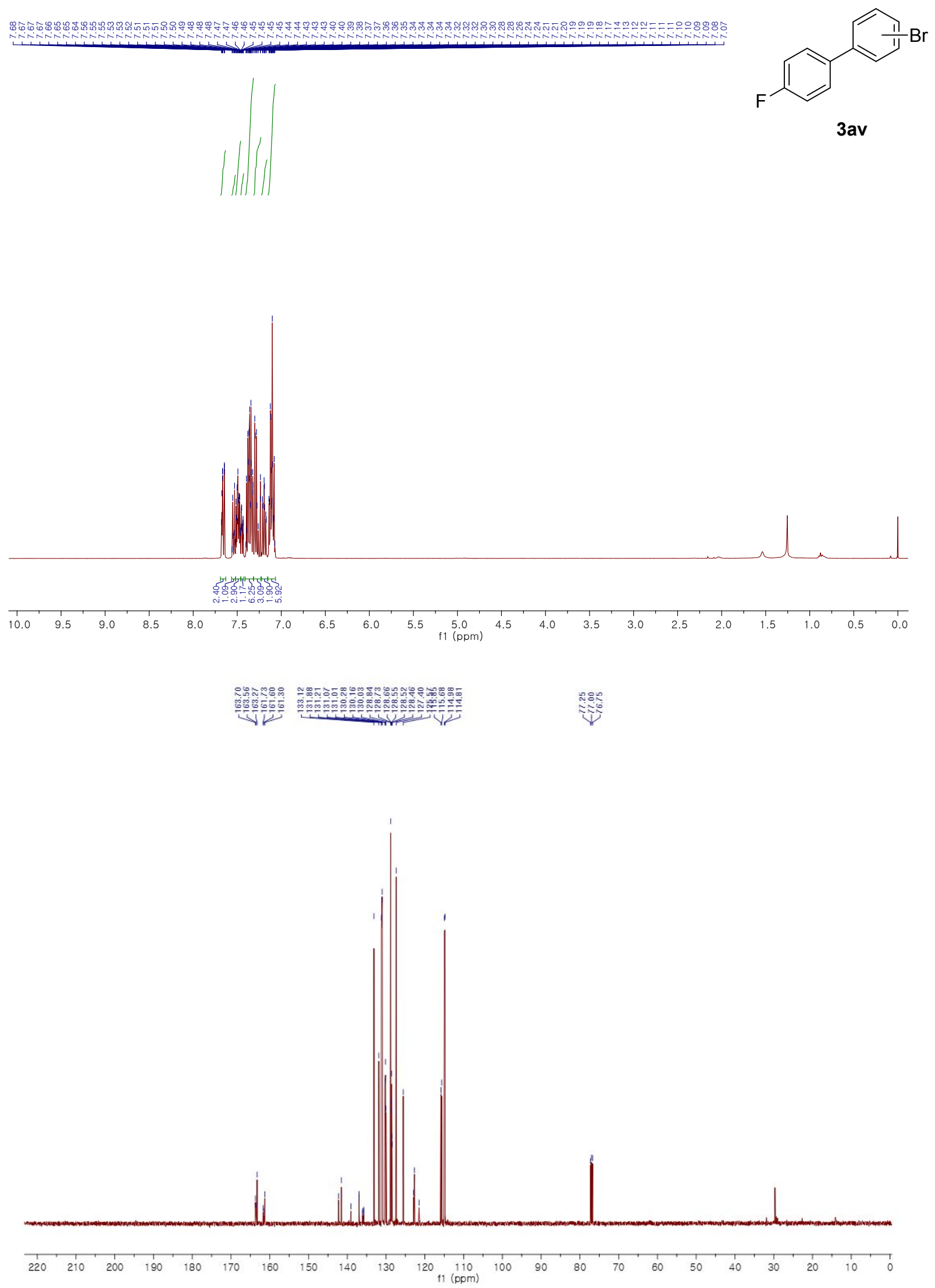

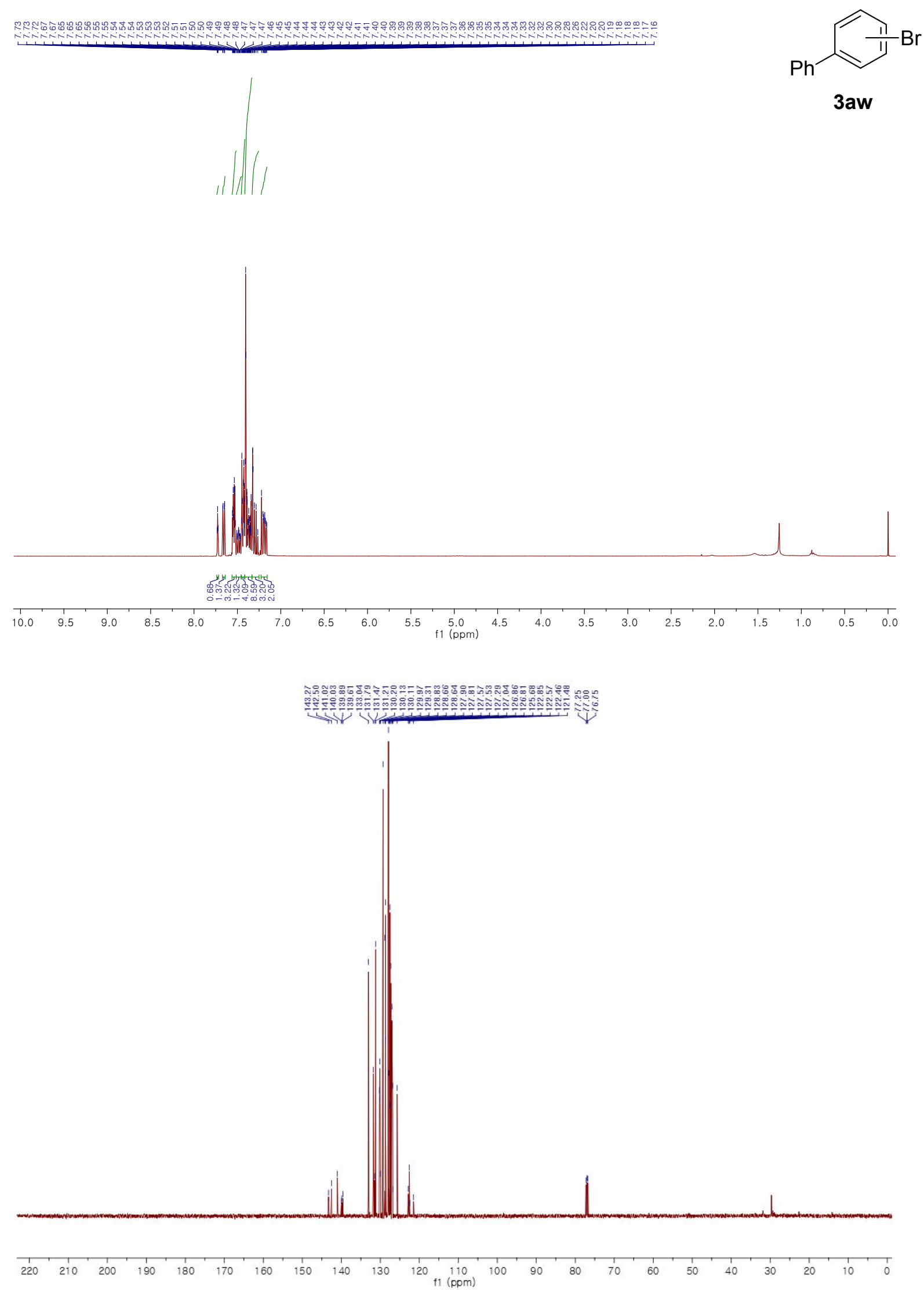


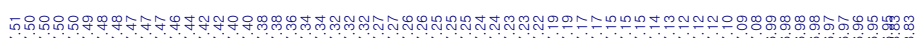
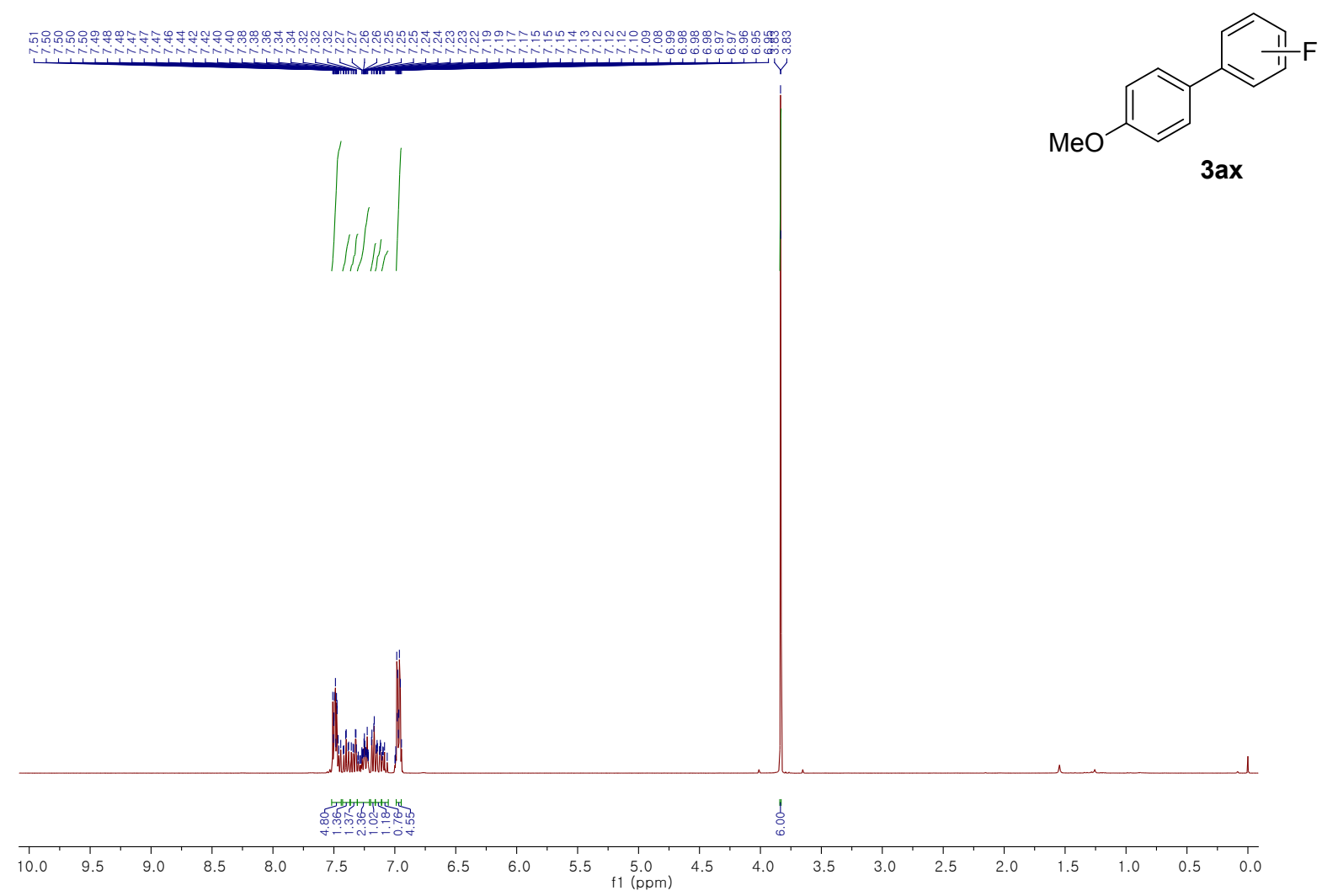

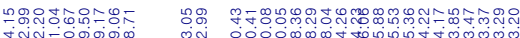

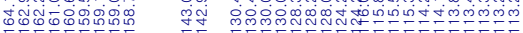

तो

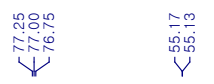

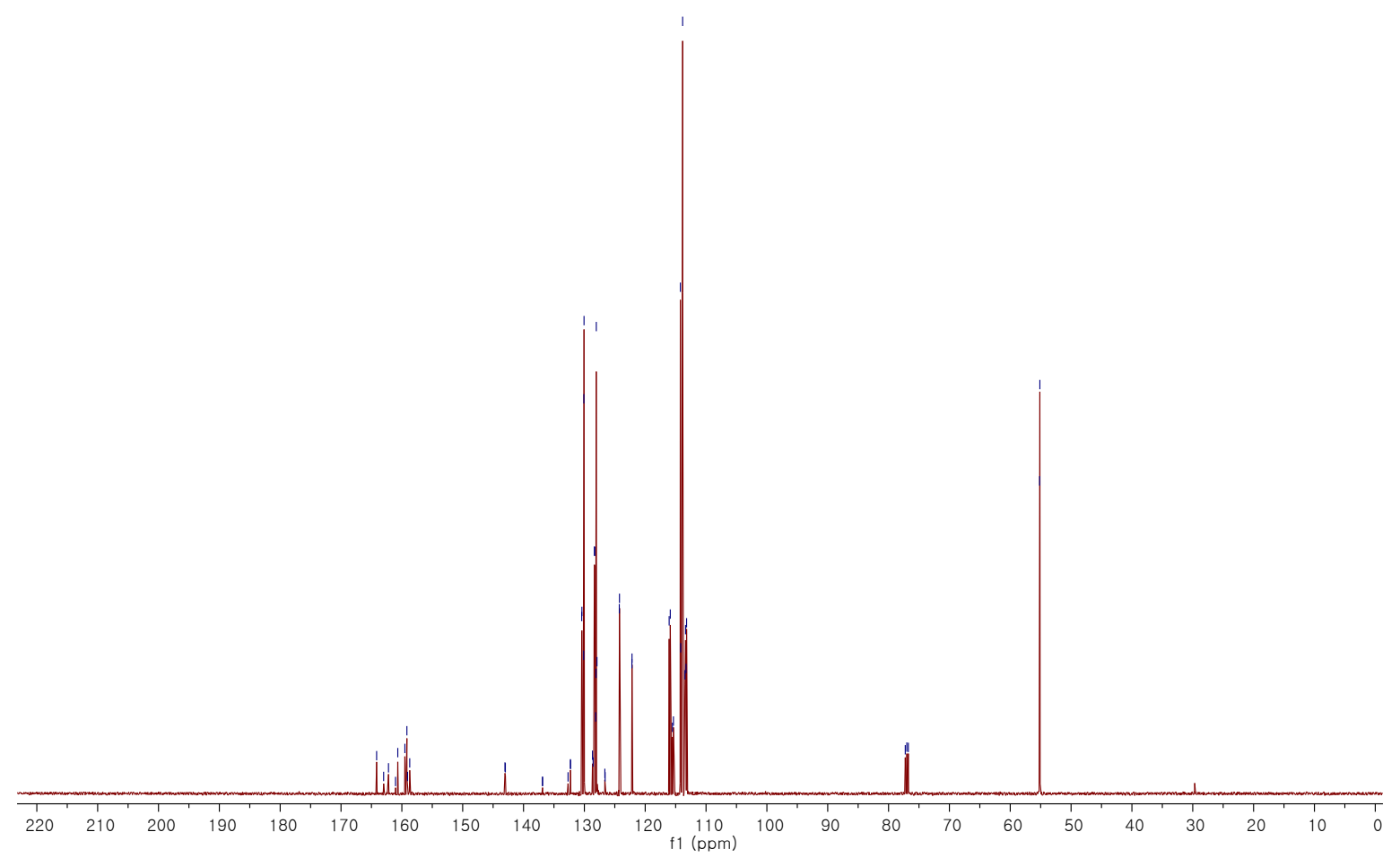


<smiles>c1ccc(-c2ccccc2)cc1</smiles>

3ay
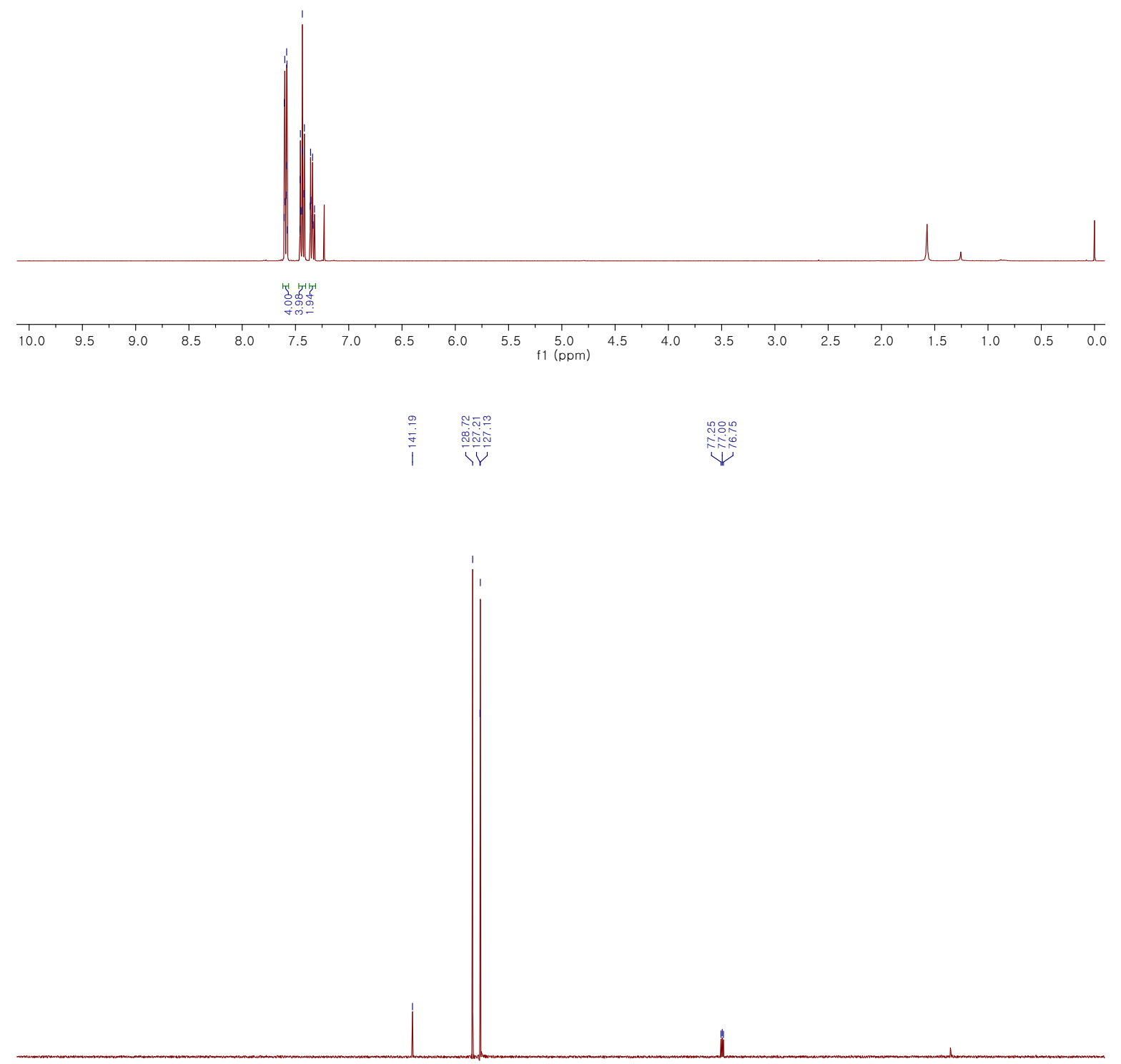

$\begin{array}{lllllllllllllllllllllllll}1 & 1 \\ 220 & 210 & 200 & 190 & 180 & 170 & 160 & 150 & 140 & 130 & 120 & \begin{array}{c}110 \\ \mathrm{f} 1(\mathrm{ppm})\end{array} & 100 & 90 & 80 & 70 & 60 & 50 & 40 & 30 & 20 & 10 & 0\end{array}$



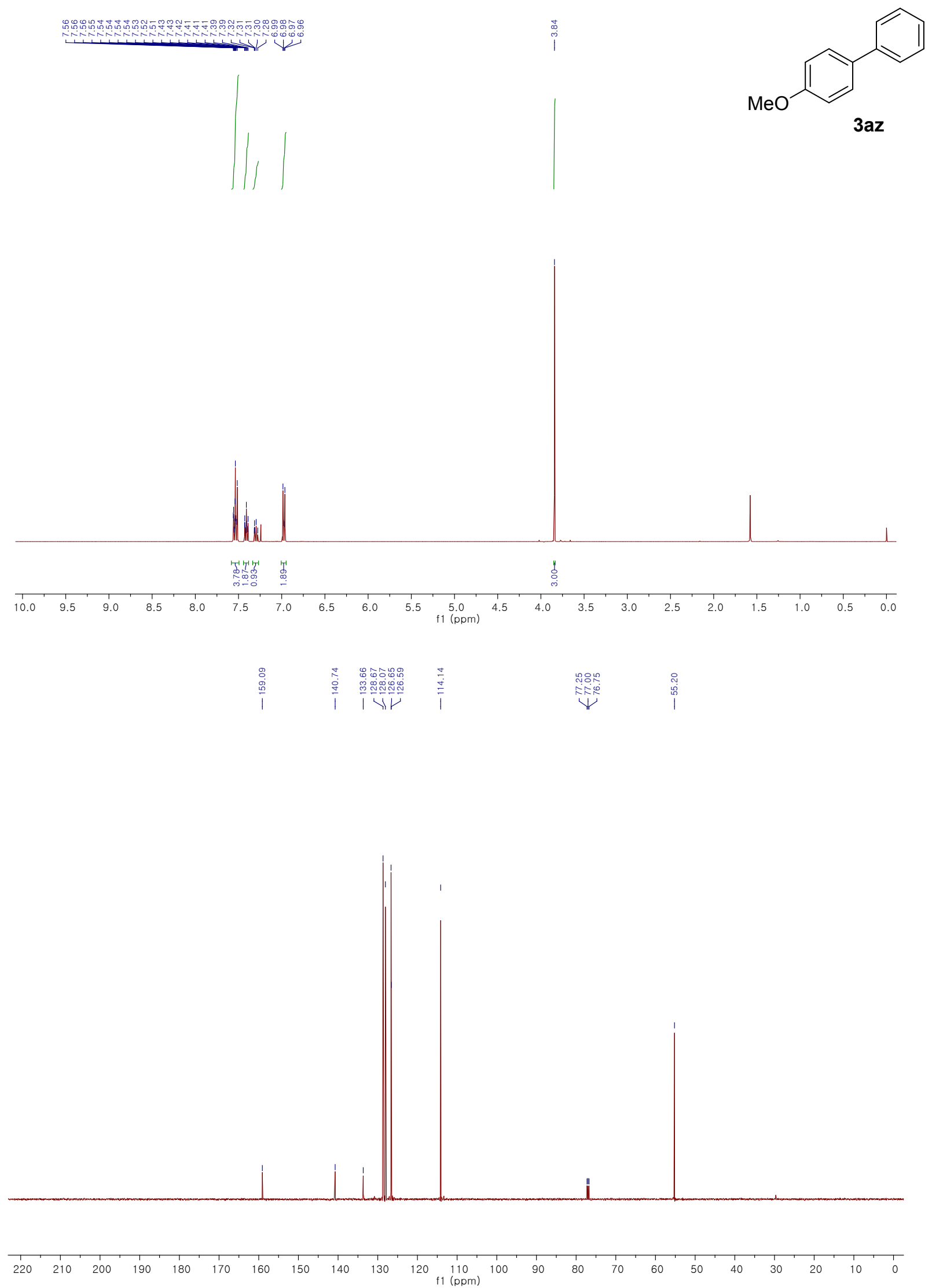


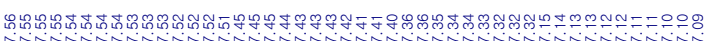
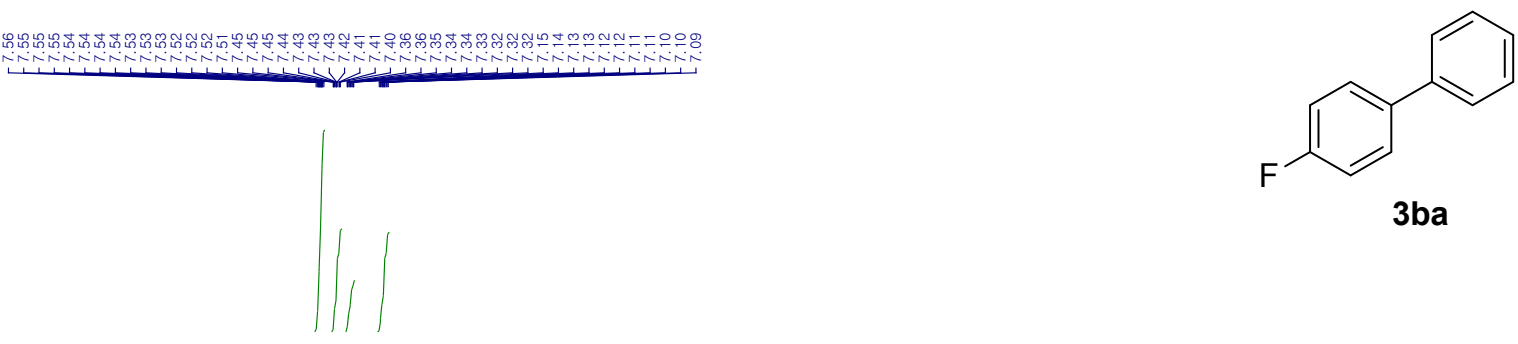

3ba
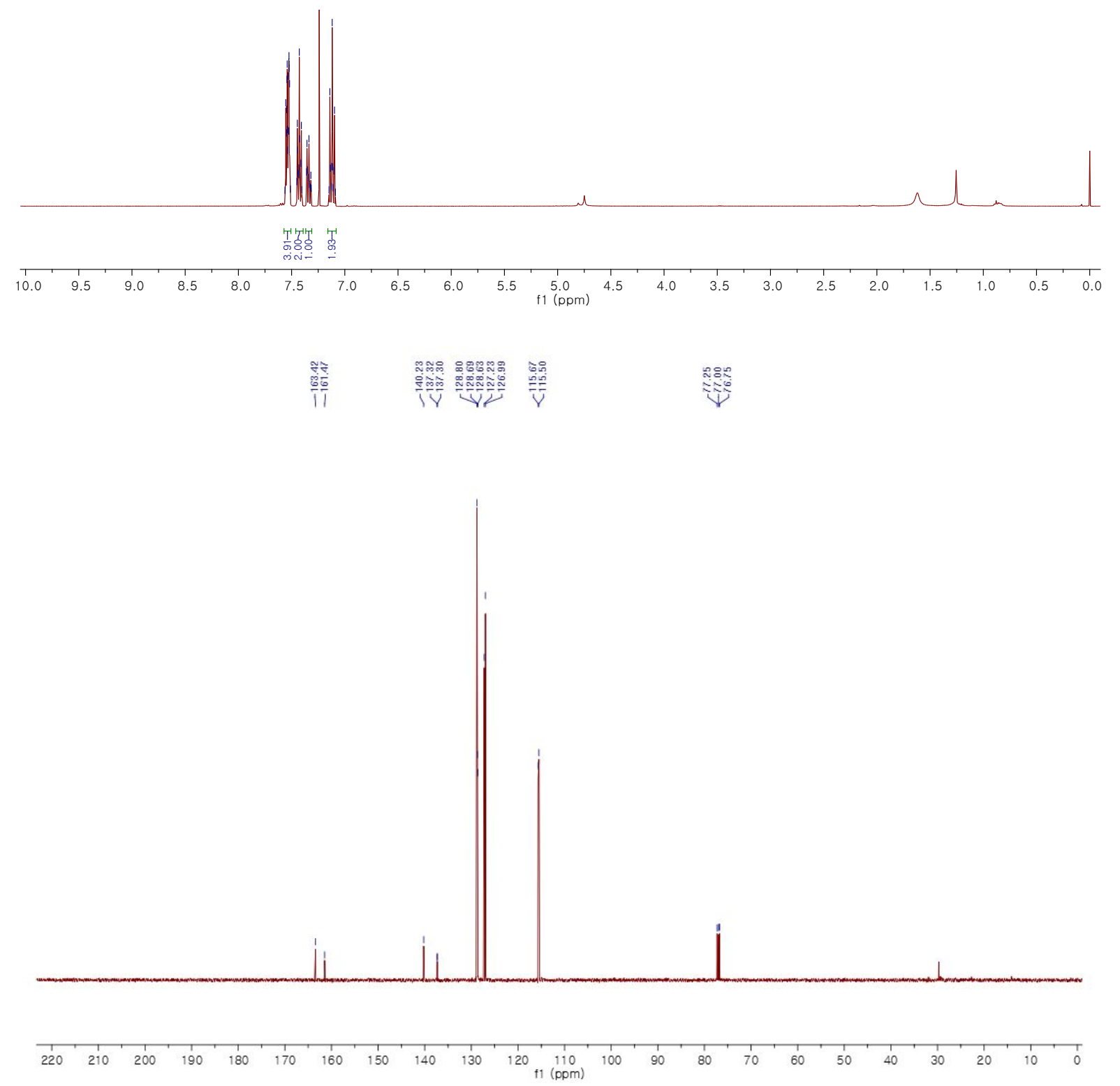


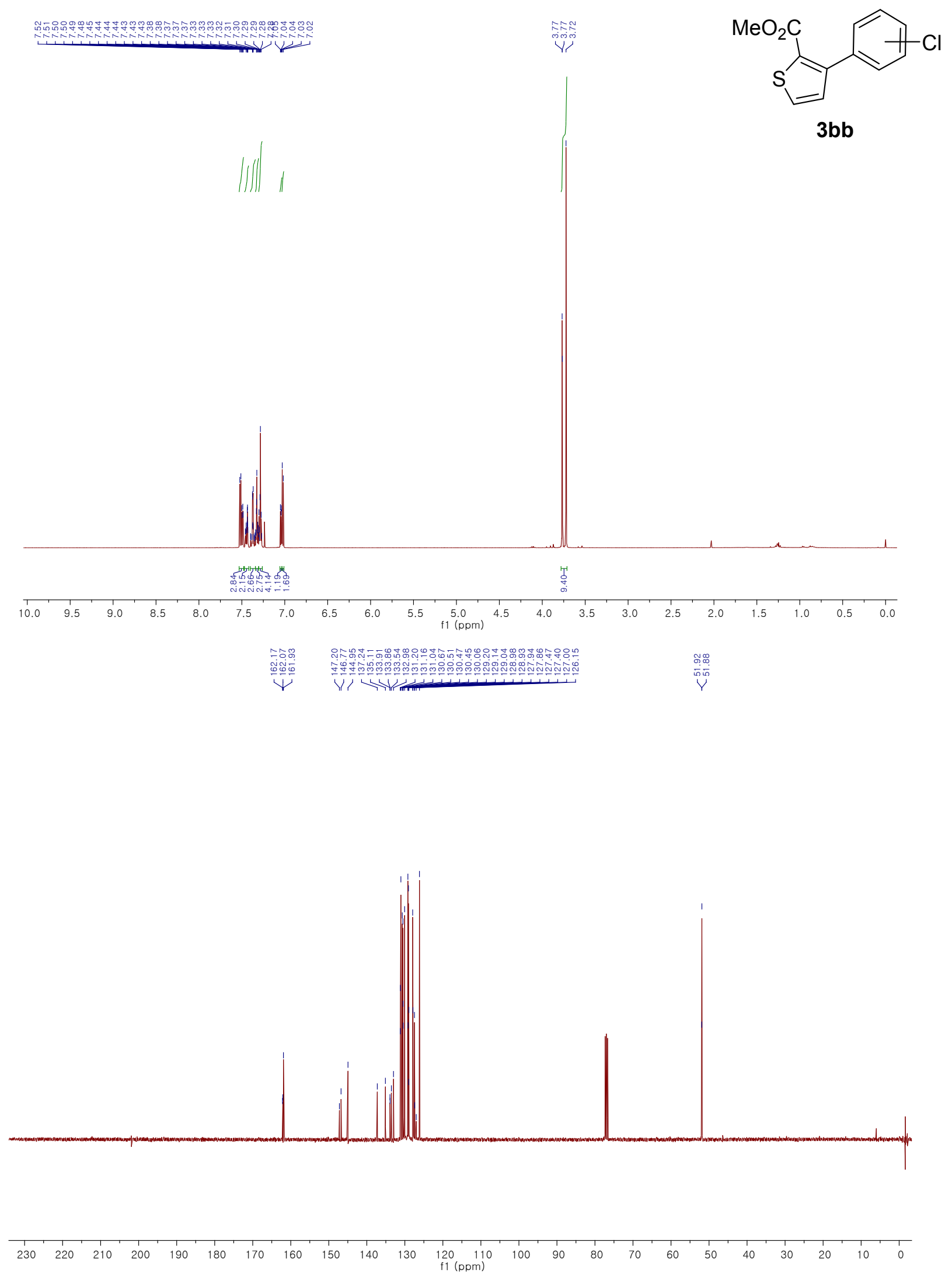



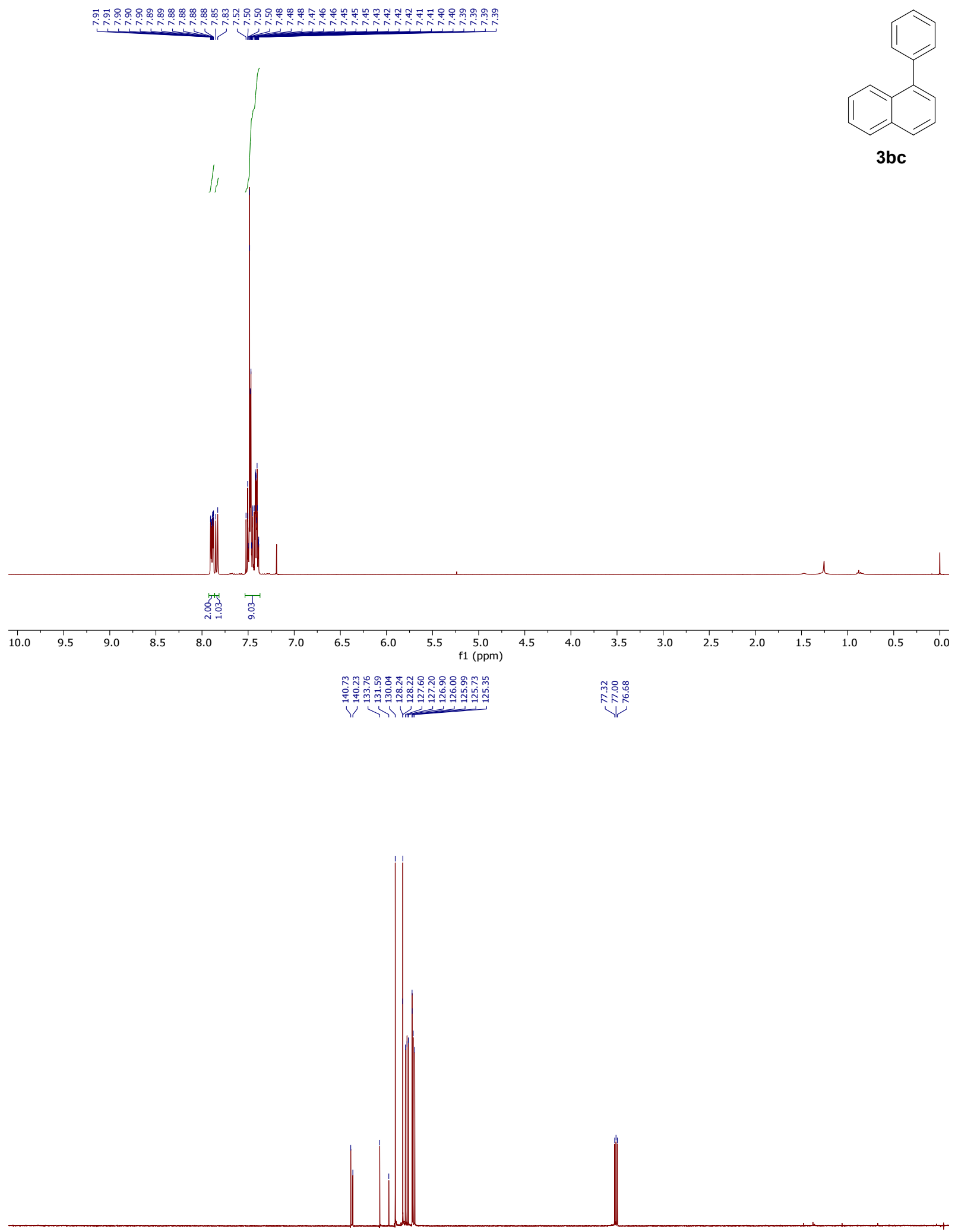

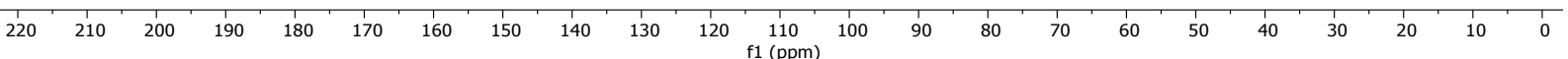



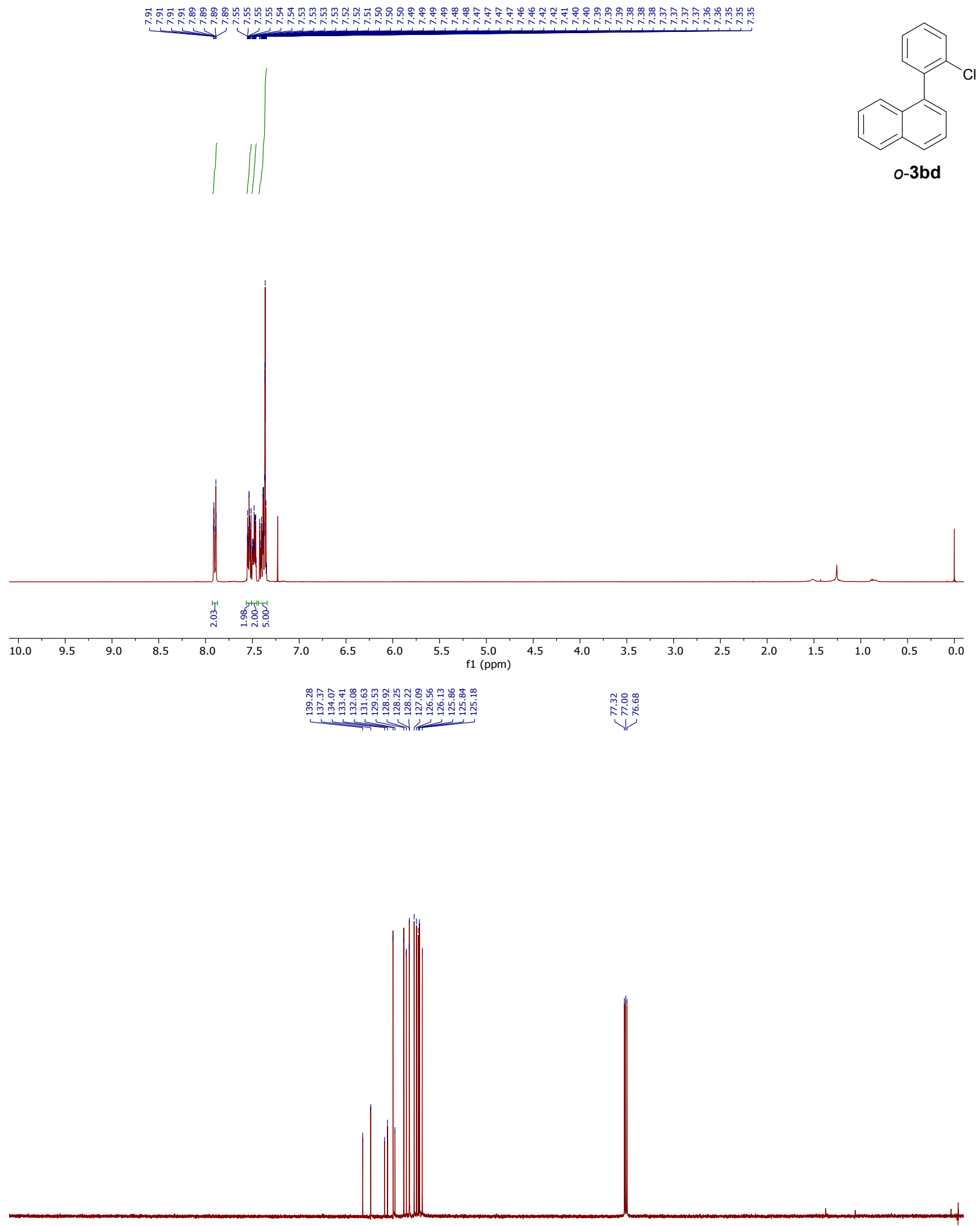

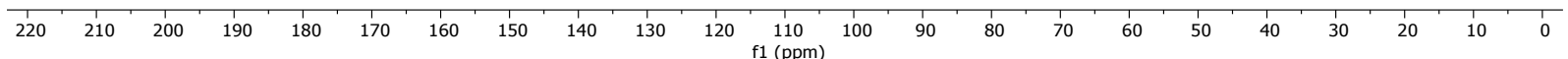



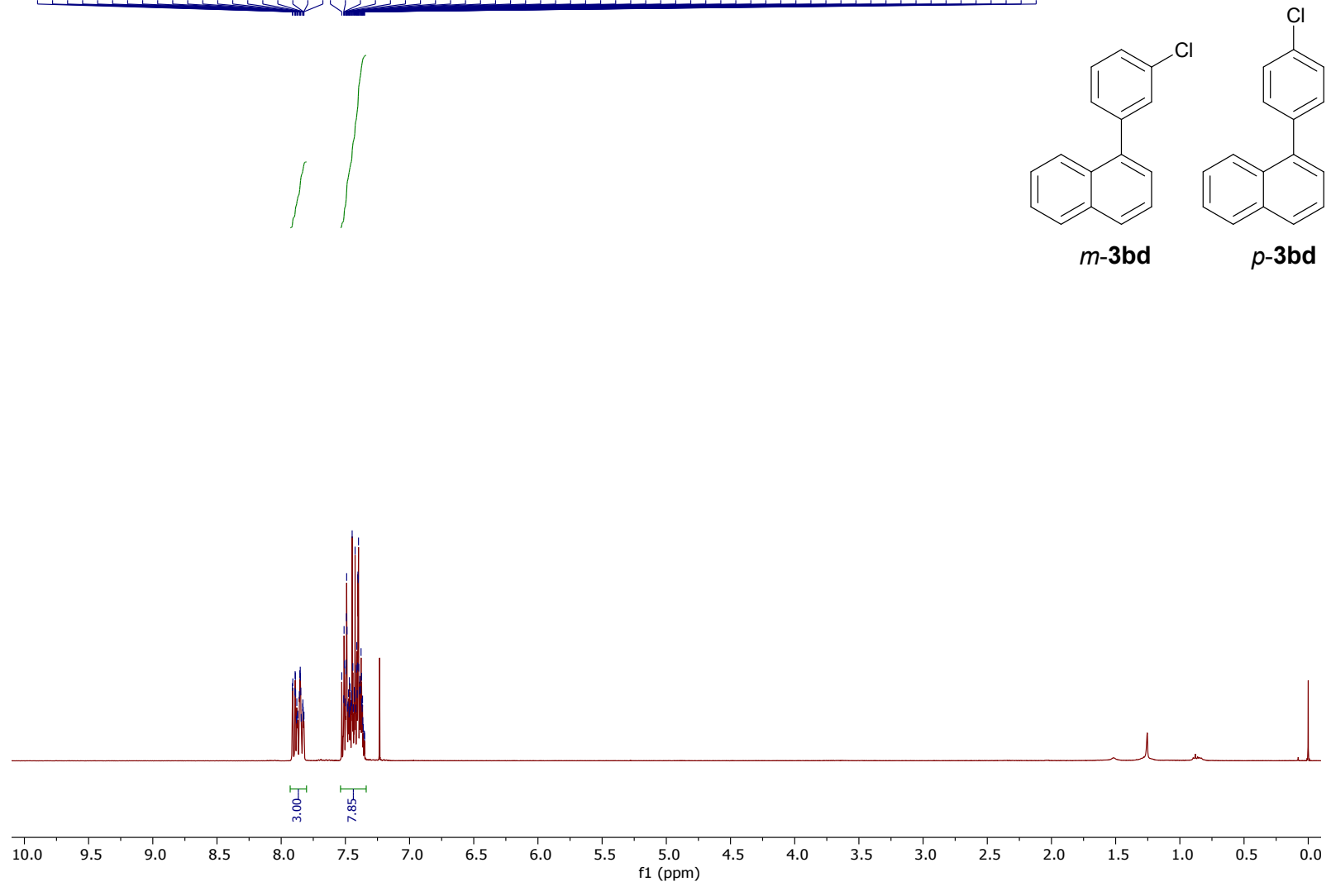

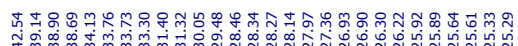

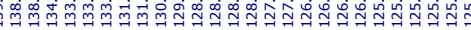

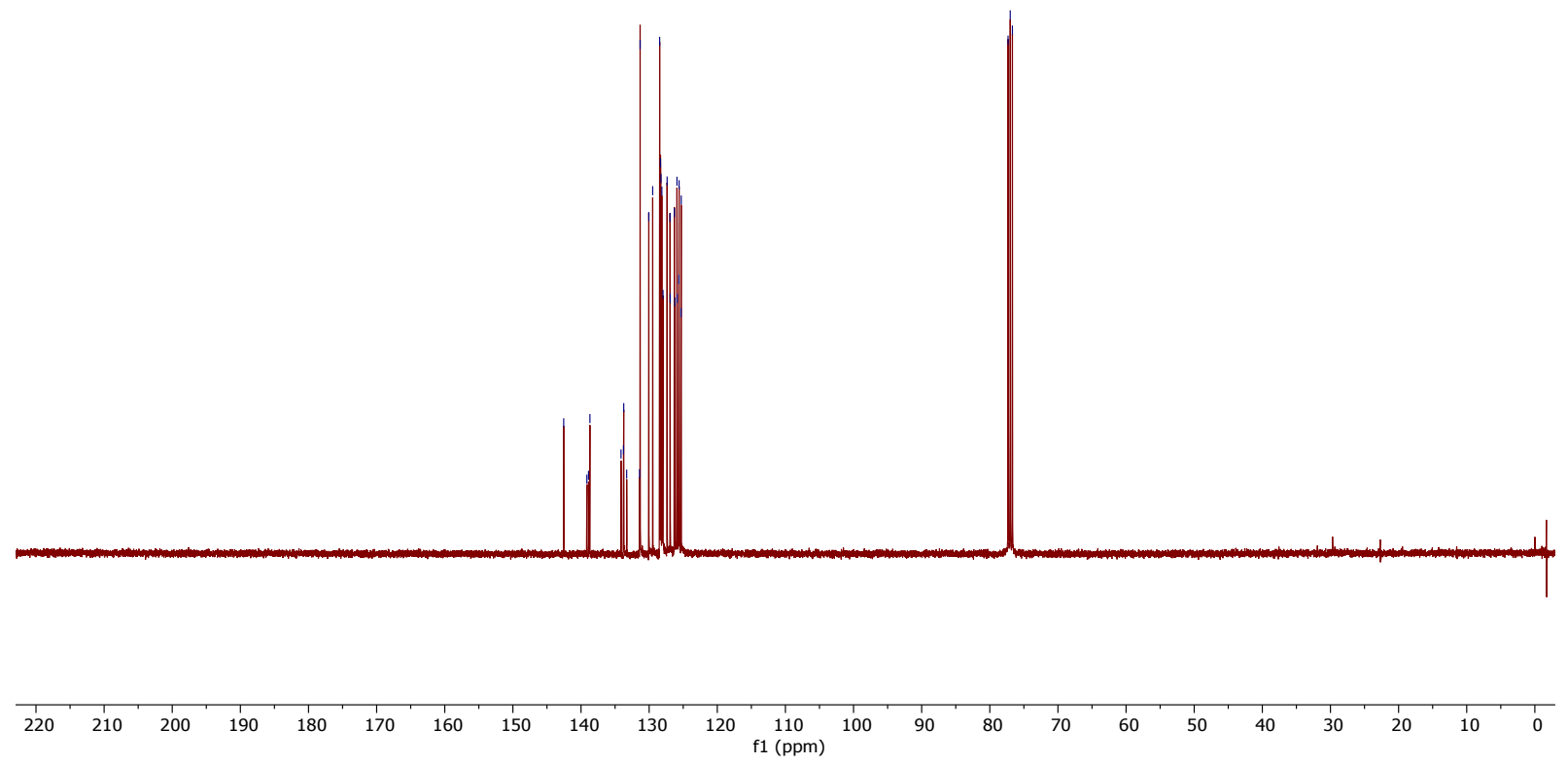



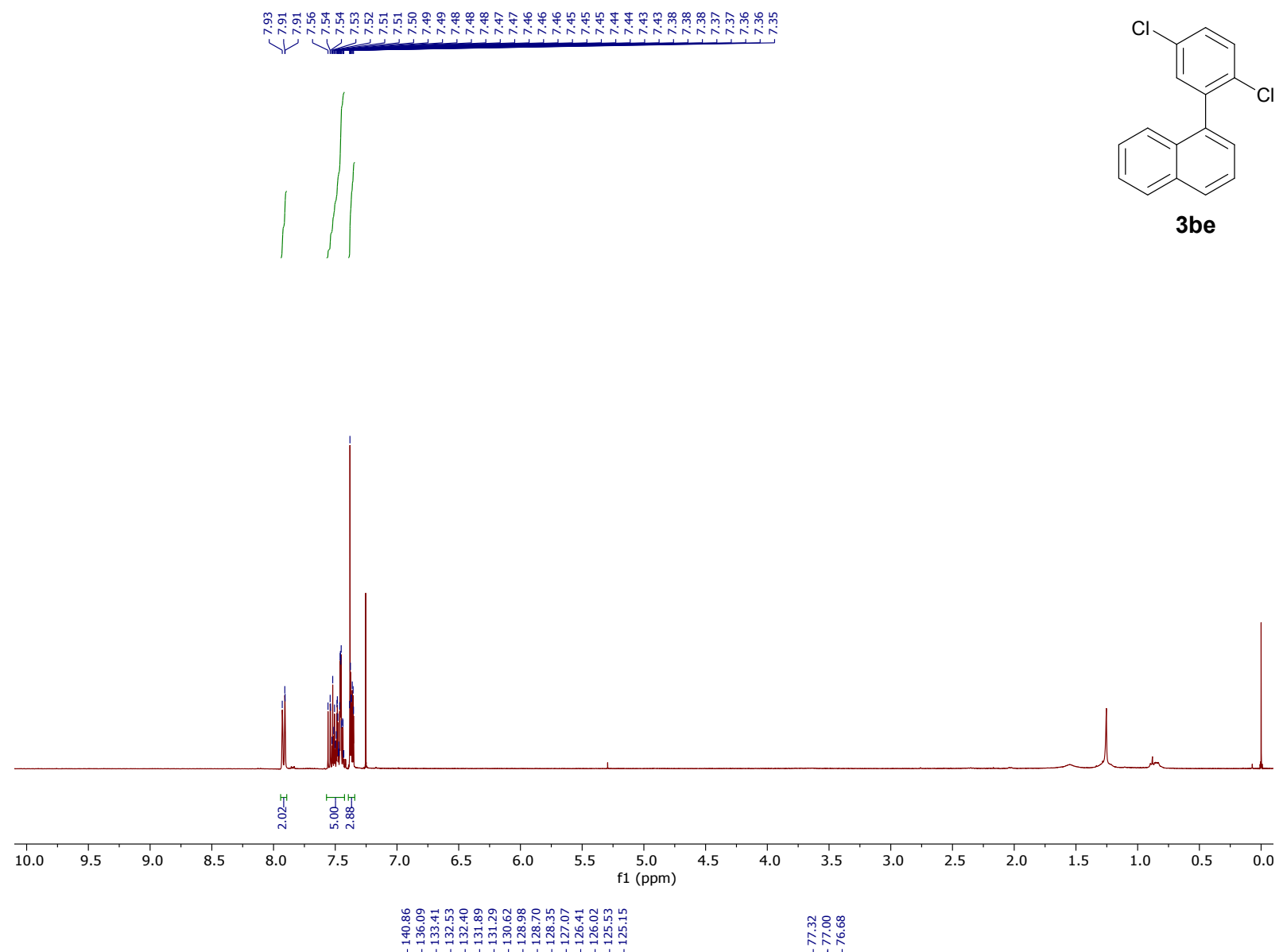

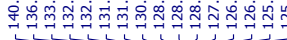

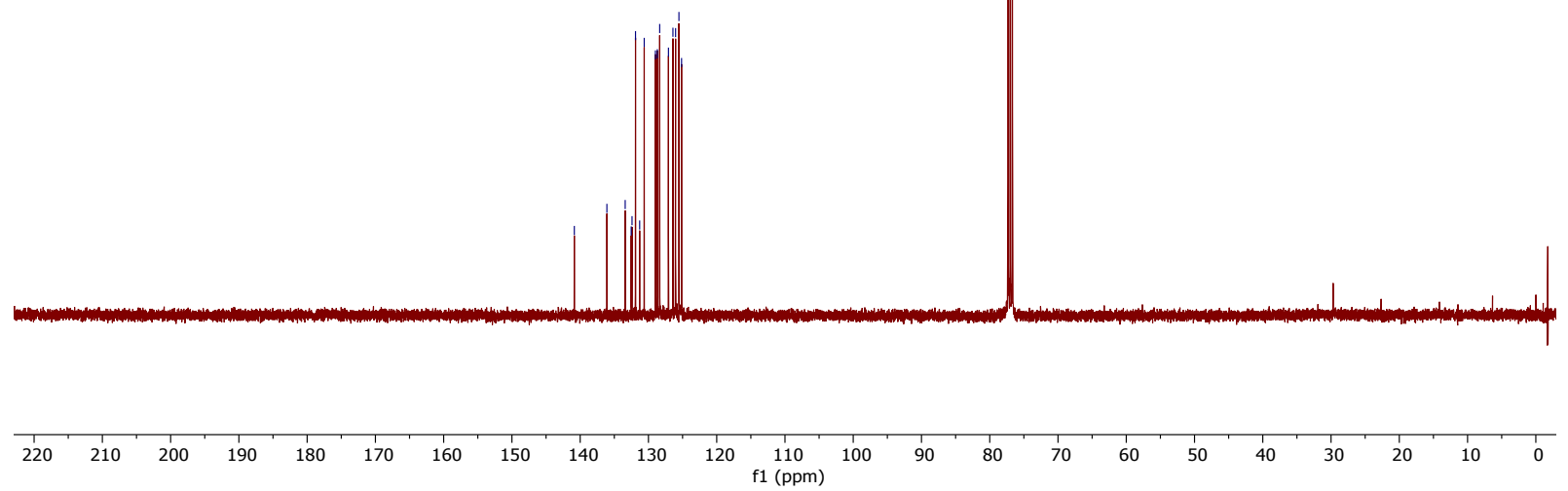



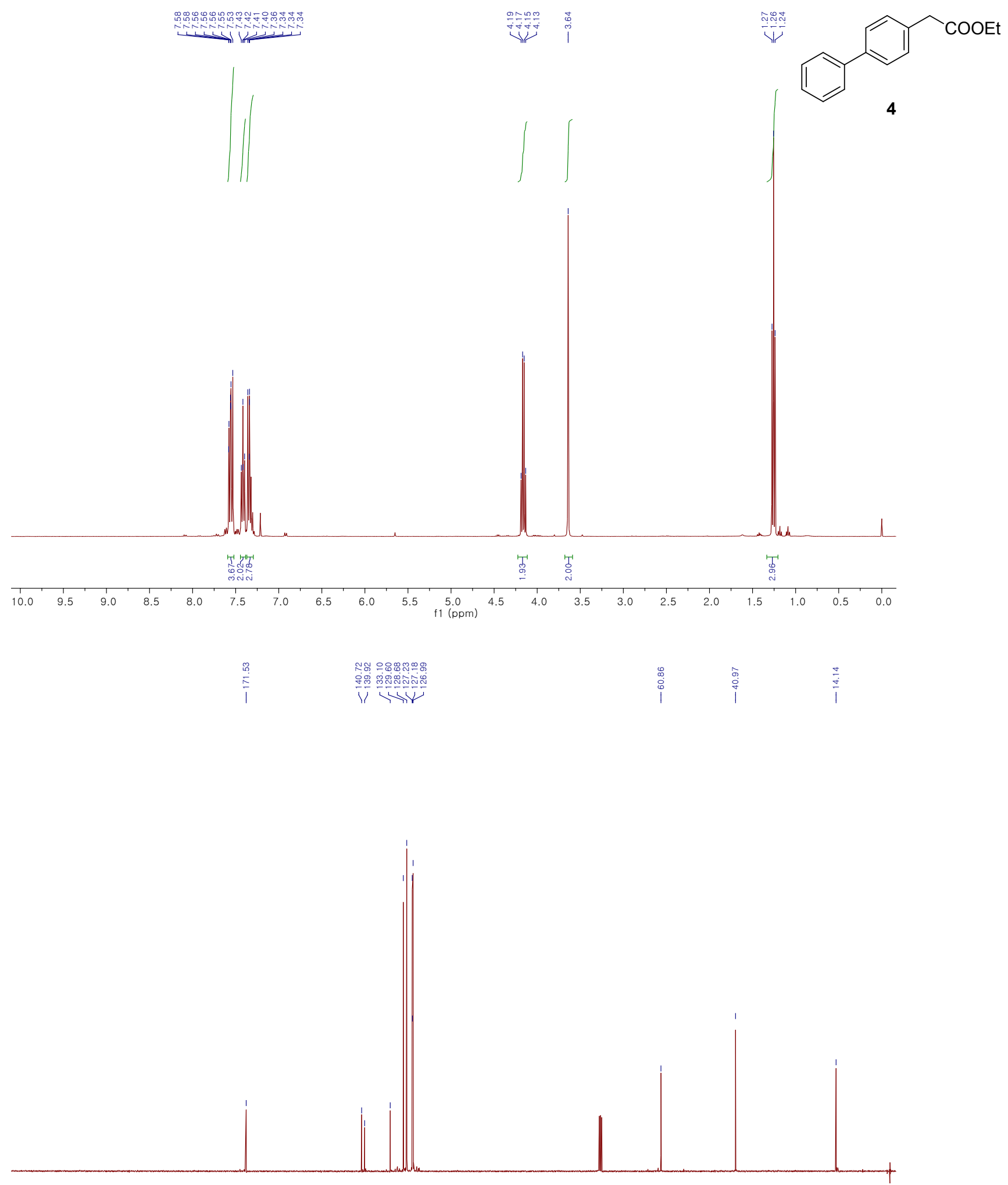

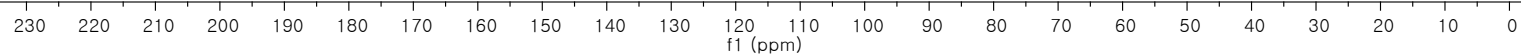




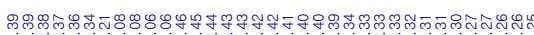

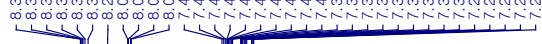

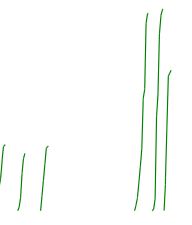<smiles>O=C(Nc1ccccc1-c1ccc(Cl)cc1)c1cccnc1Cl</smiles>

5
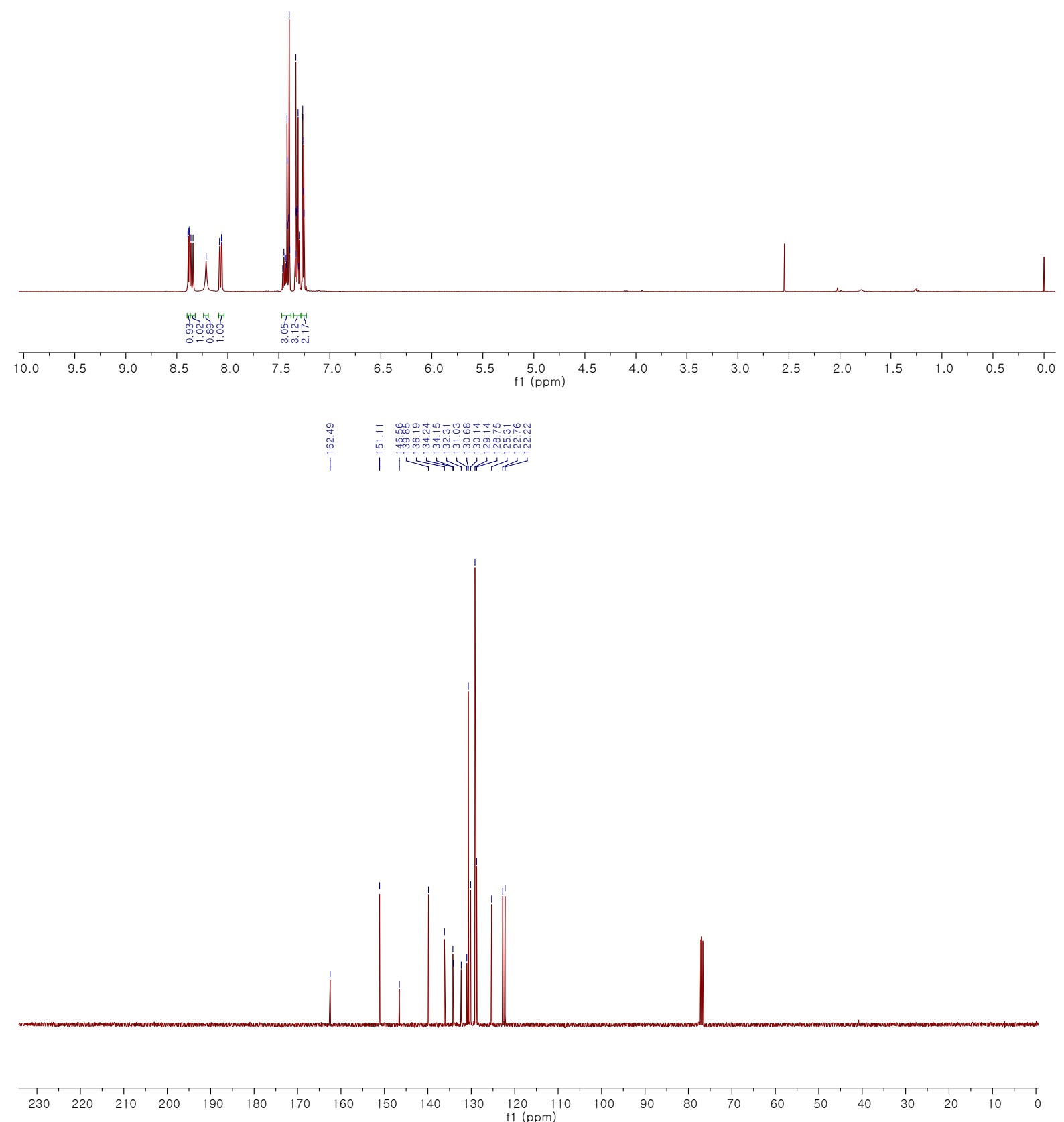